\title{
Disciplining Role of Auditor Tenure and Mandatory Auditor Rotation
}

\author{
A Dissertation \\ SUBMITTED TO THE FACULTY OF \\ UNIVERSITY OF MINNESOTA \\ BY
}

Aysa Dordzhieva

IN PARTIAL FULFILLMENT OF THE REQUIREMENTS FOR THE DEGREE OF DOCTOR OF PHILOSOPHY

Adviser: Frank Gigler

June, 2017 
(C) Aysa Dordzhieva, 2017 


\section{Acknowledgements}

I am grateful to my dissertation committee Frank Gigler (advisor), Chandra Kanodia (chair), Gaoqing Zhang, Ivy Zhang, and Jan Werner for their invaluable guidance and support. 


\section{Dedication}

This dissertation is dedicated to the memory of my beloved brother, Ochir Dordzhiev. 


\begin{abstract}
This study addresses the international debate over whether the rotation of audit firms should be mandatory. Mandatory rotation rules have been adopted by the European Union, but have not been established in the United States. Proponents of the policy believe that a long tenure auditor-client relationship leads to the auditor building an excessive economic bond with the client which erodes auditor independence. Motivated by this claim, I build a theoretical model that compares auditor incentives to issue independent reports under the regimes with and without mandatory rotation. The model demonstrates conditions under which mandatory rotation could impair auditor independence, contrary to the popular view.
\end{abstract}




\section{Table of Contents}

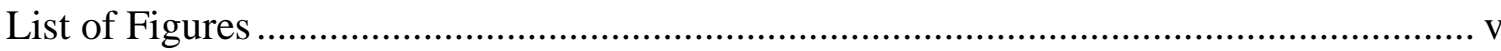

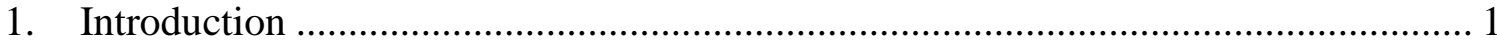

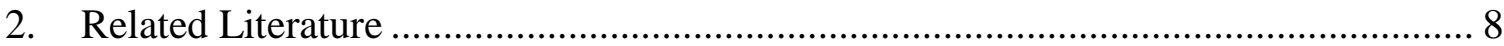

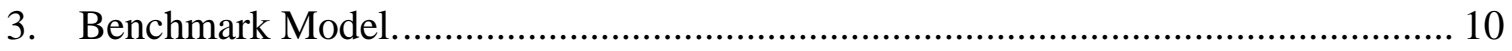

3.1. Benchmark model without mandatory rotation. ....................................... 10

3.2. Benchmark model with mandatory rotation. .......................................... 15

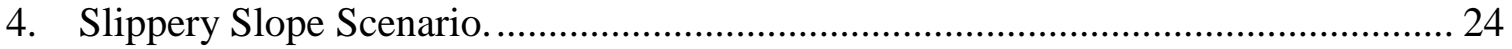

4.1. Slippery slope model without mandatory rotation.................................... 24

4.1. Slippery slope model with mandatory rotation........................................ 35

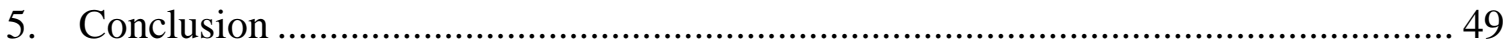

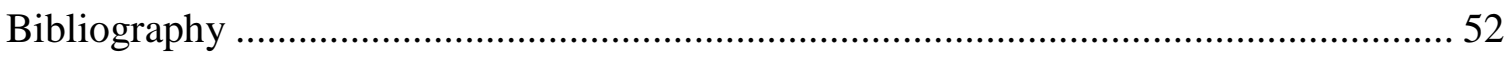

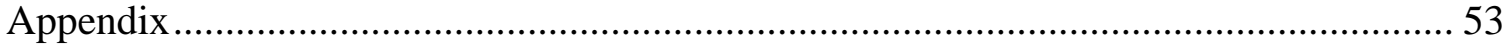




\section{List of Figures}

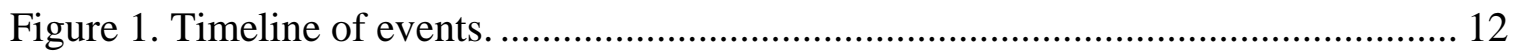

Figure 2. Decision tree in the benchmark model. ................................................. 13

Figure 3. Decision tree in the mandatory rotation case. ............................................ 17

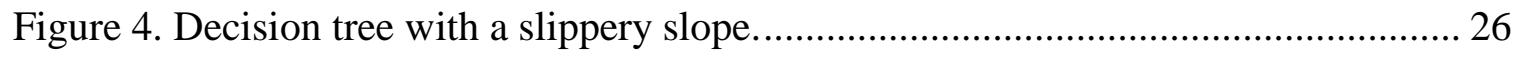

Figure 5. Decision tree in the mandatory rotation case with a slippery slope. ................ 37 


\section{Introduction}

After the collapse of Lehman Brothers Holding Inc., auditors were blamed for contributing to the 2008 global financial crisis by signing off on questionable accounting practices. The Big Four auditing firm Ernst \& Young, Lehman's watchdog, was involved in a four-year legal fight and eventually paid a $\$ 10$ million penalty for approving Lehman's accounting maneuver to hide excessive leverage. The other three major accounting firms - PricewaterhouseCoopers, KPMG, and Deloitte - all had clients that collapsed or were bailed out by governments or other institutions. As a result, investors and regulators voiced concerns about the ability of auditors to prevent fraud and misstatements.

One proposed response to these concerns was to make the rotation of auditors mandatory for public companies. In April 2014, the European Parliament adopted a strong proposal requiring European-listed companies, banks, and financial institutions to appoint new audit firms at 10-year intervals. The term limits are expected to enhance audit firm independence, and therefore, increase audit quality. Meanwhile, in the US, the Public Company Accounting Oversight Board (PCAOB) solicited public comment on a 2011 proposal mandating audit firm rotation. This proposal was eventually defeated after almost three years of debate when Congress passed a bill amending the Sarbanes-Oxley act of 2002. The amendment went as far as to prevent the PCAOB from requiring public companies to rotate their auditors. Still, the PCAOB chairman pledged to keep the project on its activity list and continue discussions on the matter.

The logic behind these reforms is that auditors are the gatekeepers that preserve 
credibility in capital markets. They issue public reports on the reliability of financial information, and they make sure that the information contained in the reports reflects the truth. To trust these reports, investors need to be confident that auditors provide independent and unbiased certification. Proponents of the mandatory rotation believe that a long-term engagement can lead auditors to become too aligned with the client and lose their professional skepticism (Conference Board, 2003; IESBA; Ryan et. al, 2001). Mandatory rotation is intended to both bring a fresh look to the auditing task and break economic bonds that can erode the independence of the auditing firm, which in turn impairs audit quality. Opponents of the policy argue that audit quality increases with longer tenure because of improved auditor expertise and superior knowledge about the client and that audit failures actually happen more often on new engagements (GAO, 2003; Johnson et al., 2002). As a result, the debate is often pinned down to examining a tradeoff between auditor independence and auditor competency, the two principal components of audit quality.

In this paper, I focus on the effect of mandatory rotation on auditor independence, the key issue on which this regulation was targeted. If the benefits from the improved auditor independence overweigh the costs from implementing mandatory rotation requirements, then the overall result will have a positive effect on the audit market. However, if mandatory rotation fails to improve auditor independence, then, with decreased auditor competency, it will result in an impaired audit quality.

I build a theoretical framework to analyze auditor incentives to issue independent judgements. I find that the rotation requirement does not necessarily make the auditor 
more independent. In a market where an auditor's independent report may reveal information about his past wrongdoings, the auditor's optimal choice is to continue accommodating the client if he biased the report to favor the client at an earlier time. As a result, the prospect of getting penalized once this misbehavior is eventually discovered has an important disciplining effect on an auditor's decision as to whether to accommodate a client in the first place. The mandatory rotation provides the auditor with an opportunity to interrupt the course of bad choices; and therefore, ironically, the initial decision to compromise his independence becomes comparatively less costly. Furthermore, in a regulatory regime without mandatory rotation, if the auditor's chances of finding a good long-term replacement for a problematic client are high, the auditor will be more willing to drop her. Since mandatory rotation truncates all future client engagements, the value of finding a good replacement is also truncated, hence the auditor's incentives to prematurely drop a current client decline. I show that these two forces may overweigh the benefits of the rotation regime, and therefore, that mandatory rotation can erode auditor independence.

I first introduce a simple economy where a firm hires an auditor to receive financing for a project from investors. A project can be "good" or "bad" with probabilities $\mu$ and $1-\mu$, respectively. A good project results in positive cash flows with certainty and therefore should be financed. A bad project may fail with a nonzero probability. I assume that investors do not finance bad projects and that a firm in which projects fail to receive financing must close down.

I model an auditor as a long-term player who maximizes the expected present value of his 
profits. I limit an auditor to having one client at a time. In each period he learns the project quality as a result of conducting the audit. For ease of exposition, I assume the auditor perfectly learns the quality of his client's project but the analysis is easily generalized to the case where the auditor's information is imperfect. The auditor then releases an audited report to the market. The auditor's revenues are the fees received for the audit services provided to the clients. If the auditor believes the project is bad, he may choose to disclose this to investors or he may choose to certify the client's report. If he discloses that the project is bad, based on this information, investors will refuse to finance the project, and the firm will have to shut down. Since the auditor loses the client, he incurs switching costs to start a new client engagement. Switching costs represent an auditor's expenses for finding a new client, transitioning, and becoming familiarized with a new business as well as the intangible losses of relationship capital. If the auditor certifies the client's report, he keeps the client unless the project fails. If the project fails, the market learns that the auditor ignored his information, and the auditor has to pay a penalty. This penalty includes litigation costs and auditor's resources spent on reputation recovery. Thus, in each stage in which the auditor examines a bad quality project, he faces the following dilemma: to keep the client and risk being exposed if the project fails or to reveal his information and incur switching costs. Consequently, the auditor solves the problem by attempting to minimize both the number of switches and the exposure to the risk of incurring penalties.

I first use this framework to build a simple benchmark model that elucidates the forces which make the mandatory rotation regime beneficial. I start by uncovering the drivers of 
the auditor's decision in the no-rotation regime. In the benchmark model, the auditor operates in a market where all firms are homogeneous (in the sense that all of them may produce both good and bad projects with the same level of uncertainty), and the quality of the projects independently changes from period to period. In such a market, an auditor has no inherent preferences over which firm to audit. However, it is easy to see that if the auditor's switching costs are higher than some threshold level, he prefers to keep even a client he believes to be bad and take the corresponding risks. This threshold level will be determined by the auditor's expected penalty. Thus, high switching costs create an economic bond between the auditor and the client, which facilitates less independent reporting in equilibrium.

I show that there are two forces by which mandatory rotation fosters auditor independence. The first is the benefit espoused by those arguing in favor of mandatory rotation. In the last period of his engagement, since an auditor must switch clients accommodating a bad client has no value.

The second benefit of mandatory rotation in the benchmark model is more subtle. Since the mandated switch is costly, an auditor with time preferences would rather delay this cost. By not certifying a client's report, the auditor incurs an immediate switching cost, but postpones the time of the compulsory switch. Therefore, in the mandatory rotation regime, voluntary resignation helps an auditor avoid penalties for misbehavior as well as delay the moment of rotation. As a result, an auditor has more incentives to issue truthful reports and remain independent.

In the benchmark model, the auditor's incentives to issue reports that favor a client 
despite his own beliefs to the contrary are rather weak, and mandatory rotation is unambiguously desirable because it creates forces that prevent the auditor from becoming too economically bound to his clients.

Next, I modify the model to allow firms to differ in the quality of projects they produce. In the modified model, I demonstrate how an auditor may go down a "slippery slope" if hired by a client with poor performance. If he chooses to favor the client the first time, then, subsequent unbiased reporting would reveal that the client's performance has been misrepresented in the past. Since, the auditor does not want to be penalized for the past, and furthermore, the underlying reasons that triggered the first wrongdoing still hold, he decides to misrepresent the client's performance again. In the model, I show that the auditor becomes trapped into a sequence of repeated biased reporting despite the risk of being exposed each time he issues another biased report. Dropping the client without revealing the past choices is not an option either. Since the market anticipates that auditors do not leave clients who have good performance, such a move would reveal information about the past as well. Hence, if the auditor accommodates the client once, he must continue to accommodate the client until one of the audited projects fails and the truth is revealed.

An interesting effect unfolds when I analyze the auditor's reporting strategy in the period before he goes down the slippery slope. First, a rational auditor anticipates such a scenario and therefore tries to avoid it by reporting the bad performance of the client when it is first discovered, thereby preserving independence. Second, the quality of the auditor's outside opportunities may provide additional incentives to issue an unfavorable 
report, since he then returns to an external market with a good chance of getting a better client; as a result, the auditor becomes more willing to terminate an engagement with a bad client. Together, these two forces generate an important disciplining effect and prevent independence erosion.

However, in a mandatory rotation regime, the term limits imposed both on current and potential future engagements lead to a partial dissolution of the disciplining effect. The truncation of the current engagement leads to truncation of the expected losses associated with the prospect of sliding down the slippery slope making the anticipated consequences of acquiescing to the client's wishes less daunting. The value of returning to the external market reduces as well since the auditor loses the opportunity to establish a long-term relationship with a good client. Furthermore, since the auditor is afraid of being penalized for his past decisions, he is reluctant to disclose the true quality of the last project, contrary to the outcome in the benchmark model. These factors together may generate a sufficiently strong negative effect which overrides the positive effects of the mandatory rotation.

This paper is organized as follows. In Section 2, I compare this paper with the extant analytical literature. In Section 3, I introduce the benchmark model and derive the auditor's optimal strategies in the regimes with and without mandatory rotation. In Section 4, I modify the model to build a setting where the current firm performance conveys information about its historical performance and demonstrate how the effect of mandatory rotation reverses in the modified framework. I conclude in Section 5. 


\section{Related Literature}

A rational explanation for a decision maker committing to a course of bad actions has first been presented in Kanodia et al. (1989). The paper demonstrates how a manager makes a bad investment decision in order to avoid damaging his reputation by revealing information about his past choices.

Corona and Randrawa (2010) show how reputational concerns lead an auditor to repeated fraudulent behavior. They model an auditor's reputation formation in a dynamic setting, where the auditor interacts with a manager and receives reputation-based payoffs based on the market's perception of his ability. If the market receives information questioning the auditor's ability to detect fraud, the auditor's reputation drops. Therefore, an auditor, who seeks to maximize his payoff is reluctant to reveal any information that implies the presence of missed fraud in past.

This paper shifts the focus from the auditor's reputation formation to the analysis of how the length of an auditor's tenure affects his motivation to misrepresent the client's performance. I adopt an infinite-period setting and model an auditor making a reporting decision based on both his evaluation of the risks associated with repeatedly misrepresenting the current client's performance and his expectation of the profits from future engagements. This setting helps to understand how an auditor balances the tradeoff between short-term losses and long-run damages. I show that imposing a limit on the length of the auditor's client engagements may negatively affect the auditor's incentives to remain independent.

Gigler and Hemmer (2008) also demonstrates an adverse effect of limiting the horizon of 
decision makers in a renegotiation setting. They identified conditions under which putting a limit on the number of rounds of renegotiation makes the decision parties strictly worse off.

There is a scarce amount of analytical literature that analyzes the implications of mandatory rotation for the audit market. Lu and Sivaramakrishnan (2009) compare investment efficiency in the regimes with and without mandatory rotation. They analyze the case where clients engage in opinion shopping and auditors might exhibit conservative or aggressive biases when attesting to clients' financial positions. Their results suggest that when opinion shopping is absent, mandatory rotation impairs investment efficiency. In the case when firms engage in opinion shopping, the effect might reverse depending on the firms' prospects. Elitzur and Falk (1996) examine changes in the planned audit quality if the required rotation is implemented, taking the auditor's independence as given. In contrast, this paper endogenizes auditor independence and examines the changes in the auditor's optimal strategies depending on the type of regulatory regime.

In this paper, the auditor's communication setting is reminiscent of Mathis et al. (2008). They construct an infinite-horizon game in which an opportunistic credit rating agency (CRA) maximizes the net present value of future payoffs. In each period, the CRA observes the quality of its client's investment project, communicates the quality to the market, and receives a payoff based on the market's perception of the accuracy of the report. The study shows that when the CRA's income largely depends on the rating products, the CRA's optimal strategy becomes inflating the ratings. 


\section{Benchmark Model.}

\subsection{Benchmark model without mandatory rotation.}

In this section, I start by introducing a very simple model, the purpose of which is to establish a baseline result. In the model, the auditor operates in a market where all firms are homogeneous (in the sense that they all may produce both good and bad projects with the same level of uncertainty), and the quality of the projects independently changes from period to period. In each period, the auditor performs an audit, learns the quality of the project, and, if it is bad, decides whether to disclose the information. I derive the auditor's optimal strategy in this static decision environment and demonstrate the basic tradeoff the auditor faces when making a reporting decision. This model is a starting point for further analysis. Then, I introduce mandatory rotation in the benchmark model. I show that if the auditor is required to periodically rotate off his audit engagements, the structure of his decision environment changes over time, as he progresses towards the end of his tenure in each of his engagements. This leads to a shift in his incentives to reveal unfavorable information about his clients. I finalize this section by comparing auditor incentives across these two settings.

There are an infinite number of firms in the economy. At each period $t=0,1, \ldots, m \ldots$, each firm seeks financing for a project that can be either good or bad, with corresponding probabilities $\mu$ and $1-\mu$, respectively. The quality of the project is a noisy signal of the cash flows that the project will generate in the future. The project quality is a priori unknown. I assume that, in the benchmark model, all firms are identical and can generate both good and bad projects. Good projects result in positive cash flows with probability 
1. Bad projects may fail with nonzero probability. I denote the chance of the bad project being successful with a probability $\lambda$. All projects last one period. If the project ends successfully, then the firm starts a new project.

After the firm starts the project she seeks an investment. She learns the quality of the project and makes an unaudited financial report. If the project is bad, I assume that the manager misrepresents its financial position to survive and continue into the next period. However, investors do not trust unaudited reports and the firm must hire an auditor to add credibility to the reports.

An auditor is a long-term player with a discount factor $\delta \in(0,1)$. The auditor maximizes the expected present value of his profits. For each period of time an auditor can audit one firm. At the beginning of the period $t$, he has no information about the firm's performance. I denote the auditor's initial information state as $s_{t}^{1}=n$ ( $n$ for "no" information). Then, he examines the firm and learns the firm's project quality. If the project is good, he transitions to the information state $s_{t}^{2}=g$, in which he certifies the firm's report, and receives an audit fee $f$. Since a good project generates cash flows with certainty, the auditor keeps the firm and avoids switching. If the project is bad, the auditor's information state becomes $s_{t}^{2}=b$. In this state, he takes an action $a$ out of a set $\left\{a^{b}, a^{g}\right\}$, where $a^{b}$ is disclosing information about the project quality to the market, and $a^{g}$ is ignoring the information and certifying the firm's report. If the auditor discloses that the project quality is $b$, then the firm fails to receive financing and must shut down. Thus, the auditor receives the fee $f$ for the completed audit but incurs a switching $\operatorname{cost} C$ to find a new client and gain new client-specific knowledge. The switching cost is 
observable only to the auditor. If the auditor chooses to certify the firm's report, he receives the fee $f$ and potentially avoids the switching cost. However, he faces the risk of the true project quality being revealed if the project fails. If the project succeeds (with a probability $\lambda$ ), the auditor keeps the firm. If the project fails, the market learns that the auditor chose to ignore this information. In this case, he incurs a penalty $R$, which can include litigation costs and expenses on reputation recovery. In addition to the penalty, the auditor switches and pays the switching cost $C$ since the exposed firm must shut down. Figure 1 depicts the timeline of events for each period.

Figure 1. Timeline of events.

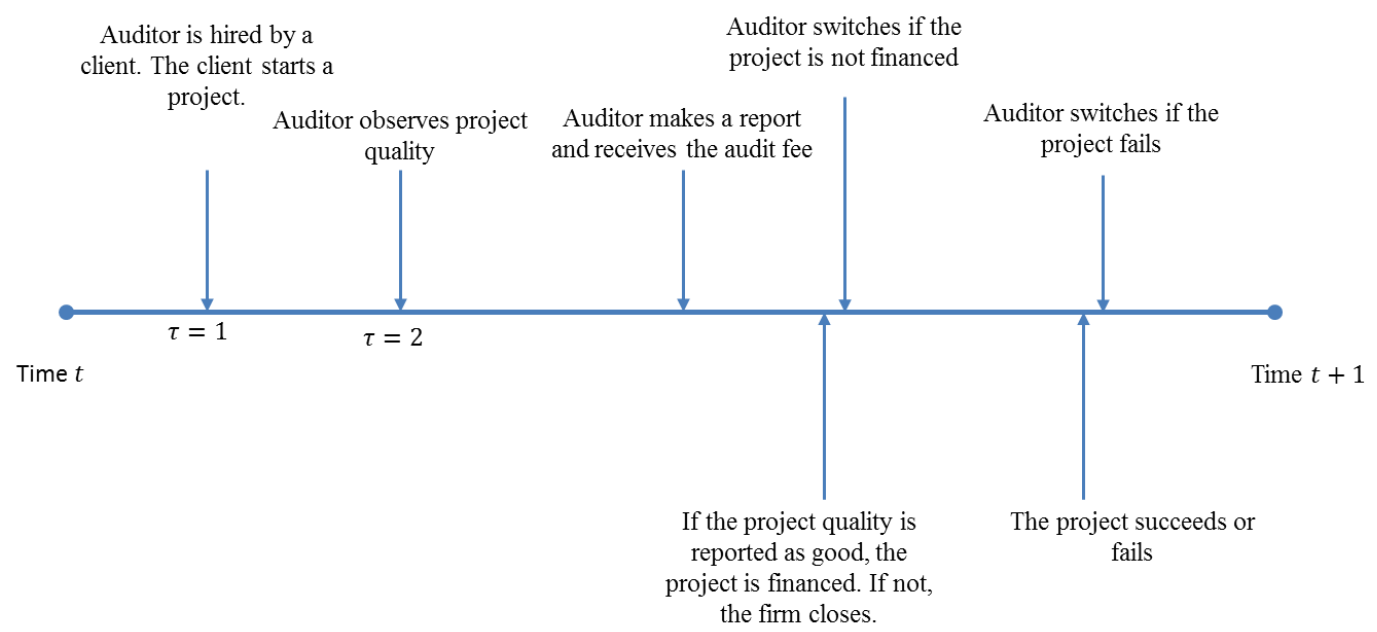

After the auditor receives the payoffs, the firm takes on a new project. Since in the benchmark model I assume that all firms are identical and can generate either good or bad projects, the auditor does not have any knowledge about the new project, regardless of whether he kept the old client or switched to a new client. This means that, at period $t+1$, the auditor's information state resets to $s_{t+1}^{1}=n$, and the auditor solves the same decision problem. The decision tree is illustrated in Figure 2. 
I denote the auditor's payoffs in each period $t$ by $\pi_{t}\left(s_{t}^{2}, a_{t}\right)$, where $a_{t}$ is the action taken at state $s_{t}^{2}$. If the auditor achieves a state in which he does not take action, then $\pi_{t}\left(s_{t}^{2}, a_{t}\right)=\pi_{t}\left(s_{t}^{2}\right)$. The auditor's utility function $V_{t}(n)$ at the beginning of any period $t$ is the expected discounted sum of the future payoffs $\pi_{j}(),. \forall j>t$, received in each of the future periods:

$$
V_{t}(n)=E\left[\sum_{j=t}^{\infty} \delta^{j-t} \pi_{j}\left(s_{j}^{2}, a_{j}\right)\right]
$$

Next, I derive the auditor's optimal strategy in this simple setting. Since at this point the auditor operates in a static decision environment, it suffices to examine a one-shot decision problem. Proposition 1 demonstrates the baseline result.

Figure 2. Decision tree in the benchmark model.

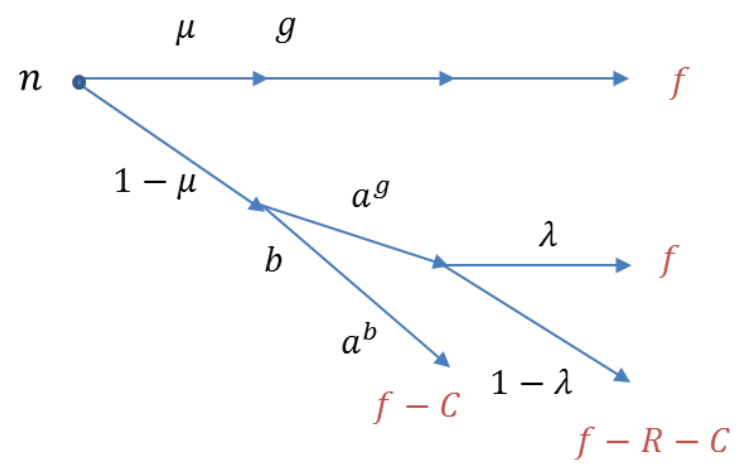

Proposition 1. The optimal strategy of the auditor is to disclose the bad quality of the client's project if $C \leq C^{*}$, and accommodate the client by certifying her report if $C \geq C^{*}$, where $C^{*}=\frac{R(1-\lambda)}{\lambda}$.

Proof: 
To determine an optimal strategy, it suffices to find which action is preferred in each oneshot decision stage $s_{t}^{2}=b$. The auditor's optimal strategy is $a^{b}$ if and only if:

$$
\begin{gathered}
f-C \geq f+(1-\lambda)(-R-C), \\
(R+C)(1-\lambda) \geq C .
\end{gathered}
$$

Intuitively, this inequality represents the auditor's tradeoff when he discovers that the audited project is of bad quality. The right-hand side is the switching costs he pays if he terminates the engagement voluntarily by exposing the client. The left-hand side incorporates the risk of being forced into switching due to project failure.

The reduced form yields the following result:

$$
a=a^{b}, \text { if } C \leq C^{*} \text { and } a=a^{g} \text { if } C \geq C^{*} \text {, where } C^{*}=\frac{R(1-\lambda)}{\lambda} .
$$

Proposition 1 illustrates how an auditor forms an economic bond with a client, which impedes independent reporting. If the auditor's actual switching costs are larger than the threshold level $C^{*}$, he prefers to keep the client by certifying her report even if he believes that the quality of the client's project is bad. This threshold level is determined by the auditor's expectation of being penalized if the audit failure becomes public. If the auditor estimates his chances of being exposed as high and expects larger penalties, then his switching costs may drop lower than the threshold level, and the auditor is better off resigning to avoid the risks associated with the client.

In the next subsection, I will introduce mandatory rotation in the benchmark model. Since the auditor is required to rotate off his clients periodically in the mandatory rotation regime, the structure of his decision environment will change over time, as he approaches 
the end of the tenure in each of his engagements. Therefore, the auditor's decision problem becomes qualitatively different from the one examined in this subsection.

\subsection{Benchmark model with mandatory rotation.}

In the mandatory rotation regime, the auditor performs a mandated switch after some fixed number of periods. In the event of the required rotation, he must drop the client regardless the type of project he audits and the actions he takes. Therefore, when the client's project is bad, the auditor essentially chooses between terminating the engagement voluntarily by revealing the project type to the market, or switching due to the mandated rotation at the end of the engagement. After the switch is performed, the auditor returns to the external market and starts a new client engagement, which also lasts no longer than some fixed number of periods. The costs associated with all these switches will then be incorporated into the auditor's objective function; hence, they will influence the strategies the auditor will pursue.

Furthermore, due to the prospect of unavoidable rotation at a predetermined point in the future, in each period of an engagement, an auditor with time preferences faces a different decision problem. These discrepancies are dictated by the proximity of the moment of incurring the rotation costs.

I adjust the benchmark model to incorporate the differences between engagement stages into the auditor's decision problem. I assume that the auditor's client engagement consists of two stages. The number of stages can be extended to any arbitrary number $m$; however, for the sake of simplicity, I consider an engagement lasting two periods. I

consider an augmented state space $\left(s_{t}^{i}, \tau\right)$, where $s_{t}^{i}$ is the auditor's information state at 
time $t, i$ represents the auditor's information acquisition process in period $t$, and $\tau$ labels the stages of an engagement.

The auditor starts an engagement from state $(n, 1)$ in which he has no prior information about the client's project. Then he learns the project quality and transitions to either $(g, 1)$ or $(b, 1)$. If the project quality is good, the auditor receives audit fee $f$. If the project quality is bad, the auditor chooses an action $a_{1} \in\left\{a^{b}, a^{g}\right\}$, where $a^{b}$ represents the auditor's choice to disclose that the project is bad, and $a^{g}$ is the auditor's option to ignore the information and certify the client's report. If the auditor chooses the action $a^{b}$, the auditor incurs switching costs $C$ and starts a new client engagement by transitioning back to $(n, 1)$. If $a_{1}=a^{g}$, his payoff depends on the project outcome at the end of the period. If the project fails with probability $(1-\lambda)$, the auditor incurs a penalty $R$ and switching costs $C$, and also starts a new engagement by transitioning to $(n, 1)$. If the project generates cash flows with probability $\lambda$, then he keeps the client and proceeds into the second stage of the engagement.

The auditor starts the second stage of the engagement from state $(n, 2)$ since he does not know the quality of the new project. Then he transitions to either $(g, 2)$ or $(b, 2)$. If the project quality is good, the auditor receives audit fee $f$ and incurs switching costs $C$ since he must rotate. If the project quality is bad, the auditor chooses an action $a_{2} \in\left\{a^{b}, a^{g}\right\}$. If the auditor chooses $a_{2}=a^{b}$, then his payoff is $f-C$, as in the first stage of the engagement. If he chooses $a_{2}=a^{g}$, he receives $f-C$, if the project generates cash flows, and $f-C-R$, if the project fails. After the rotation, the auditor starts a new client 
engagement and transitions back to $(n, 1)$. The decision tree for the two stages of the client engagement is illustrated in Figure 3.

Figure 3. Decision tree in the mandatory rotation case.
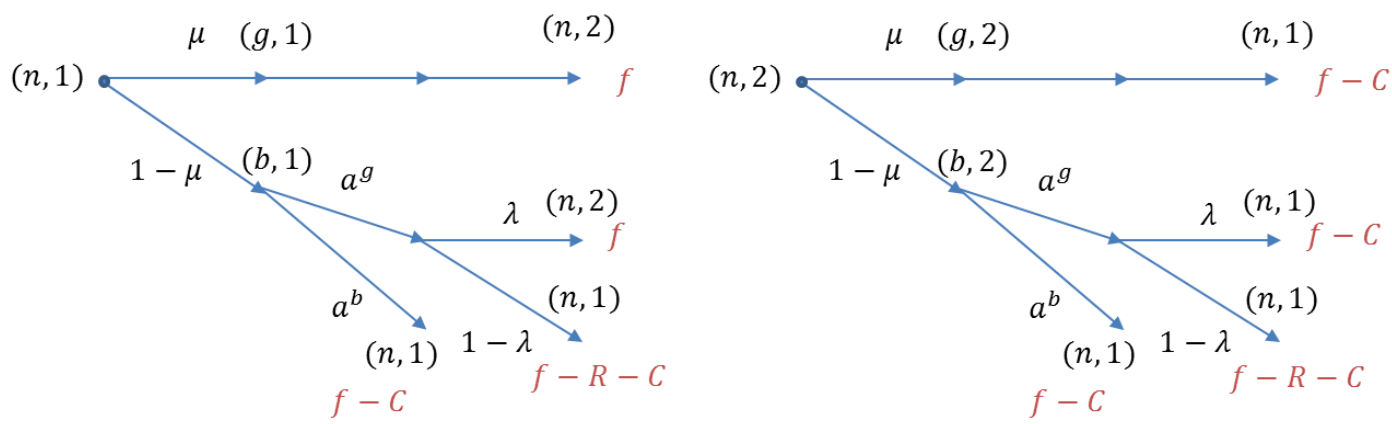

Next, I summarize the auditor's payoffs.

In the first stage of an engagement $(\tau=1)$, the auditor's payoffs are as follows:

- $\quad \pi_{t}((g, 1))=f$, if the audited project is good.

- $\pi_{t}\left((b, 1), a^{b}\right)=f-C$, if the project is bad, and the auditor chooses to reveal the information.

- $\pi_{t}\left((b, 1), a^{g}\right)=f-R-C$, if the project is bad, the auditor chooses to certify the firm's report, and the project fails.

- $\pi_{t}\left((b, 1), a^{g}\right)=f$, if the project is bad, the auditor chooses to certify the firm's report, and the project generates cash flows.

In the second stage of an engagement $(\tau=2)$, the auditor's payoffs are given by:

- $\quad \pi_{t+1}((g, 2))=f-C$, if the audited project is good.

- $\quad \pi_{t+1}\left((b, 2), a^{b}\right)=f-C$, if the project is bad, and the auditor chooses to reveal the information. 
- $\quad \pi_{t+1}\left((b, 2), a^{g}\right)=f-R-C$, if the project is bad, the auditor chooses to certify the firm's report, and the project fails.

- $\pi_{t+1}\left((b, 2), a^{g}\right)=f-C$, if the project is bad, the auditor chooses to certify the firm's report, and the project generates cash flows.

In this model, the payoffs and transition probabilities among states depend only on the current state; hence, they satisfy the Markov property. The value function $V($.$) will be$ represented by the following Bellman equations characterized for each state of the auditor's decision problem:

$$
\begin{gathered}
V(n, 1)=\mu V(g, 1)+(1-\mu) V(b, 1) \\
V(g, 1)=f+\delta V(n, 2) \\
V(b, 1)=\max \{f-C+\delta V(n, 1), f+(1-\lambda)(-R-C+\delta V(n, 1))+\lambda \delta V(n, 2)\} \\
V(n, 2)=\mu V(g, 2)+(1-\mu) V(b, 2) \\
V(g, 2)=f-C+\delta V(n, 1) \\
V(b, 2)=\max \{f-C+\delta V(n, 1), f+(1-\lambda)(-R)-C+\delta V(n, 1)\}
\end{gathered}
$$

Equations (3) and (6) represent the auditor's value function when the client's project is good. He receives the fee $f$ and then continues auditing the next project. Equations (4) and (7) describe the auditor's tradeoff when the project is bad. He maximizes the decision between two choices: action $a^{b}$, which leads to returning to the external market, and action $a^{g}$, which may trigger a penalty if the project fails. Equations (2) and (5) are the auditor's expected utility at the beginning of the respective stage of the engagement, before he observes the project quality. 
Next, in Proposition 2, I derive the auditor's optimal strategy in the mandatory rotation regime.

Proposition 2. The optimal strategy of the auditor is to disclose the bad quality of the client's project if $C \leq C^{* *}$, where $C^{* *}=\frac{R(1-\lambda)}{\lambda}(1+\mu \delta)$. If $C \geq C^{* *}$, the auditor accommodates the client by certifying her report in the first stage of the engagement and exposes the client in the second stage of the engagement.

Proof.

Part 1. I will use solution concepts for infinite discounted Markov decision processes to derive the auditor's optimal strategy (Bertsekas, 1995; Puterman, 1994). A strategy is optimal if and only if it satisfies the policy improvement criterion for MDPs. Essentially this criterion means that a strategy is optimal if there is no profitable deviation from the strategy in any of the decision-making states. I will also apply the same criterion to derive results in Proposition 3 and Proposition 5.

I start by considering state $(b, 2)$. It is easy to see that at $(b, 2)$ the auditor always chooses to disclose the bad quality of the client's project since $f-C+\delta V(n, 1)>f+$ $(1-\lambda)(-R)-C+\delta V(n, 1)$. Intuitively, because the auditor has to switch in both cases, the only difference between the strategy payoffs is the penalty the auditor may pay if he agrees to certify the firm's report. Therefore, at stage $(b, 2)$ he reveals the bad state, and $V(b, 2)=f-C+\delta V(n, 1)$. This results in $V(n, 2)=f-C+\delta V(n, 1)$.

Next, I find $V(n, 1)$, assuming that disclosure of the bad project quality is the optimal strategy for the auditor:

$$
V(n, 1)=\mu(f+\delta(f-C+\delta V(n, 1)))+(1-\mu)(f-C+\delta V(n, 1))
$$




$$
\begin{gathered}
V(n, 1)(1-\delta)(1+\delta \mu)=f(1+\delta \mu)-C(\mu \delta+(1-\mu)) \\
V(n, 1)=\frac{f(1+\delta \mu)-C(\mu \delta+(1-\mu))}{1-\delta(\mu \delta+(1-\mu))}=\frac{f}{1-\delta}-\frac{C(\mu \delta+(1-\mu))}{1-\delta(\mu \delta+(1-\mu))} .
\end{gathered}
$$

Thus, the auditor's value function at the beginning of an engagement is the discounted sum of the audit fees less the stream of the switching costs to be paid in the events of required rotation and voluntary resignation if the project is bad.

The policy improvement criterion for the auditor at state $(b, 1)$ will be as follows:

$$
\begin{aligned}
f-C+\delta V(n, 1) & \geq f+(1-\lambda)(-R-C+\delta V(n, 1))+\lambda \delta V(n, 2) \\
= & f+(1-\lambda)(-R-C+\delta V(n, 1))+\lambda \delta(f-C+\delta V(n, 1)) .
\end{aligned}
$$

Here, the terms of the inequality containing $V(n, 1)$ represent the auditor's expected utility from auditing future clients. If he switches voluntarily by choosing to disclose the bad quality of the audited project, he incurs immediate switching costs and starts a new engagement in the following period. Consequently, the value of auditing a future client, $\delta V(n, 1)$, is discounted when it enters the left-hand side of the inequality. If he chooses to certify the client's report, he may also have to switch immediately if the audited project fails. However, since it happens with a probability $(1-\lambda)$, the value from auditing future clients is $(1-\lambda) \delta V(n, 1)$. The auditor also must rotate at the end of the second period and expects to subsequently receive $\lambda \delta^{2} V(n, 1)$. Since the event is more remote and happens only if the auditor manages to keep the same client, it is discounted twice and multiplied by $\lambda$. It is easy to see that since $\delta<1$, the expected utility from auditing future clients is higher if the auditor switches immediately. I collect these terms on the left-hand side of the inequality: 


$$
\begin{gathered}
f-C+V(n, 1)\left(\delta-(1-\lambda) \delta-\lambda \delta^{2}\right) \geq f+(1-\lambda)(-R-C)+\lambda \delta(f-C) \\
f-C+V(n, 1) \delta \lambda(1-\delta) \geq f+(1-\lambda)(-R-C)+\lambda \delta(f-C) .
\end{gathered}
$$

Then, $V(n, 1) \delta \lambda(1-\delta)$ depicts the differences between the auditor's expected utilities from auditing new clients across the two scenarios.

Inserting the expression for $V(n, 1)$ yields:

$$
\begin{gathered}
f-C+\delta \lambda(1-\delta)\left(\frac{f}{1-\delta}-\frac{C(\mu \delta+(1-\mu))}{1-\delta(\mu \delta+(1-\mu))}\right) \\
\geq f+(1-\lambda)(-R-C)+\lambda \delta(f-C) \\
f-C+\delta \lambda\left(f-\frac{C(\mu \delta+(1-\mu))}{1+\mu \delta}\right) \geq f+(1-\lambda)(-R-C)+\lambda \delta(f-C) .
\end{gathered}
$$

Since the auditor receives the same stream of audit fees, regardless of the pursued strategy, the policy improvement criterion boils down to the following condition on costs:

$$
-C+\delta \lambda C \frac{\mu}{1+\mu \delta} \geq(1-\lambda)(-R-C)
$$

This inequality represents the distilled version of the auditor's dilemma in the first stage of the engagement. On one hand, he may pay a penalty and incur switching costs if the project fails. On the other hand, he incurs immediate switching costs but benefits from the earlier return to the external market.

I derive a reduced form of the inequality, which is important to understand why an earlier return to the external market generates benefits for the auditor:

$$
\begin{gathered}
-\lambda C+\delta \lambda C \frac{\mu}{1+\mu \delta} \geq(1-\lambda)(-R) \\
-\frac{C}{1+\mu \delta}=-C\left(1-\mu \delta+\mu^{2} \delta^{2}-\mu^{3} \delta^{3}+\cdots\right)=\sum_{j=0}^{\infty}(-1)^{j} \mu^{j} \delta^{j}(-C) \geq-\frac{R(1-\lambda)}{\lambda} .
\end{gathered}
$$


The sum $\sum_{i=0}^{\infty}(-1)^{i} \mu^{i} \delta^{i}(-C)$ is an alternating series, which is essentially a discounted sum of costs and cost savings that the auditor expects if a bad client is dropped. The expected costs enter the expression with a negative sign, and expected costs savings are represented by terms with positive signs. Intuitively, the auditor incurs the immediate switching costs in this scenario but avoids paying the rotation costs in the following period given that the new client starts a good project. In the second stage of this new engagement he must rotate, paying the rotation costs that would have been saved had he kept the previous client and rotated a period ago. Essentially, if each of the auditor's new clients produces good projects, he manages to continuously delay the rotation costs by one period. This sequence of delays generates a positive value in perpetuity. Thus, although the auditor incurs immediate switching costs, he benefits from postponing the moment of the required rotation.

I find the threshold level of the switching costs $C^{* *}$ :

$$
C \leq C^{* *}=\frac{R(1-\lambda)(1+\mu \delta)}{\lambda}=\frac{R(1-\lambda)}{\lambda}(1+\mu \delta)
$$

From similar derivations, I obtain that, if $C \geq C^{* *}$, then the auditor's optimal strategy becomes ignoring his private information and certifying the firm's report. For more information, see the appendix.

To summarize, the auditor's optimal action choice depends on the magnitude of the switching costs in the following way:

$$
a_{1}=a^{b}, \text { if } C \leq C^{* *} \text { and } a_{1}=a^{g} \text { if } C \geq C^{* *} ; a_{2}=a^{b}
$$

Next, in Proposition 3, I compare the auditor incentives to misrepresent the firm's project performance across the two regulatory regimes. For this purpose, I find the difference 
between the threshold levels of switching costs. Intuitively, if the auditor's actual switching costs are higher than a threshold level, he prefers to keep the client and take the risk of being exposed. This threshold level is driven by the auditor's expectation of incurring a penalty. If the magnitude of actual switching costs falls below the threshold level, the auditor is better off terminating the engagement. Hence, if the threshold level is higher in one of the regulatory regimes, that regime has a comparatively positive effect on auditor independence.

\section{Proposition 3.}

1) The threshold level $C^{*}$ in the regime without mandatory rotation is lower than the threshold level $C^{* *}$ in the mandatory rotation regime for any value of $\lambda, \mu, \delta$, and $R$.

2) Mandatory rotation improves auditor independence. Specifically, if the auditor's actual switching costs lie in the interval $\left(C^{*}, C^{* *}\right)$, then he chooses to expose the client when he first learns that the client's project is bad. If they lie outside the interval, then even if the auditor chooses to ignore the bad project quality in the first period of an engagement, he always reveals the true quality in the second period of the engagement.

Part 1. I compare the threshold levels of switching costs across the two regimes and find that:

$$
C^{* *}-C^{*}=\frac{R(1-\lambda)(1+\delta \mu)}{\lambda}-\frac{R(1-\lambda)}{\lambda}=\frac{R(1-\lambda) \delta \mu}{\lambda}>0 \forall \lambda, \mu, \delta, R .
$$

Part 2. The results in (1), (8), and (9) suggest that the auditor's action choice $a_{1}$ is affected by the change in the regulatory regime, if the auditor's actual switching costs lie 
in the interval $(R(1-\lambda) ; R(1-\lambda)(1+\delta \mu))$. If the switching costs lie outside the interval, mandatory rotation affects only the auditor choice in the second stage of client engagement, in which he always chooses $a^{b}$.

According to Proposition 3, the positive effect of mandatory rotation is twofold. When the auditor examines the last project before the rotation, keeping the engagement by accommodating the client has no value. Therefore, he prefers to disclose the quality of this project. Furthermore, since rotation is costly, an auditor with time preferences would rather delay this cost. A premature resignation provides the auditor with an opportunity to delay rotation by starting a new engagement. Hence, compared to the regime without mandatory rotation, the auditor's preferences are shifted such that he has more incentives to remain independent.

The results in the benchmark model support the popular opinion that mandatory rotation improves auditor independence. In the next section, I will demonstrate that this result falls apart if I introduce persistence in the firms' project characteristics. Under certain market conditions, mandatory rotation will still be partially beneficial, but even then, the regulation change may fail to provide the auditor with enough incentives to adequately perform his functions in all stages of the client engagement.

\section{Slippery Slope Scenario.}

\subsection{Slippery slope model without mandatory rotation.}

In this section, I modify the benchmark model to build a framework for a market where the auditor's potential clients exhibit persistence of the quality of projects they produce. I 
demonstrate in this setting that the regulation requiring mandatory rotation may lead to an outcome completely opposite to the desired effect.

In this model, firms may produce either all good or all bad projects. In other words, the project quality implicitly assumes the quality of the firm. As such, firms can be good or bad with probabilities $\mu$ and $(1-\mu)$, respectively. Good firms constantly start good projects that result in positive cash flows. The bad firms' projects may result in positive cash flows with a probability $\lambda$, and fail with a probability $(1-\lambda)$ each period.

As in the benchmark model, after the firm starts a project, she seeks financing. Investors only fund companies that issue audited reports. An auditor is a long-term player. At the beginning of the client engagement, he has no information about the firm's type. As in the previous setting, I consider an augmented state space $\left(s_{t}^{i}, \tau\right)$, where $s_{t}^{i}$ is the auditor's information state at time $t, i$ represents the auditor's information acquisition process in period $t$, and $\tau$ labels the stages of an engagement. I denote the auditor's initial state as $\left(s_{t}^{i}, \tau\right)=(n, 1)$. Then he perfectly observes the project's quality, and infers the firm's type. The auditor, therefore, transitions either to $(g, 1)$, or to $(b, 1)$, with respective probabilities $\mu$ and $1-\mu$. The auditor may disclose the information to the market (action $a^{b}$ ) or prefer to ignore it (action $a^{g}$ ), depending on the costs and rewards he receives from pursuing the respective strategies. As in the previous settings, if the auditor chooses to reveal negative information about the firm, the firm does not receive financing and must close. As such, the auditor receives the audit fee $f$, incurs switching costs $C$, and starts a new client engagement (i.e., transitions to state $(n, 1))$. If he ignores the information, he may be exposed with probability $(1-\lambda)$, if the project fails, and incur 
costs the penalty for misreporting $R$ and switching costs $C$. He may also proceed to the next stage of the client engagement if the project does not fail with probability $\lambda$.

In the second stage of the engagement, the auditor already knows the quality of the client's project, since he learned it in the previous period. Therefore, the auditor directly transitions to state $(g, 2)$ or $(b, 2)$ depending on whether the firm's projects are good or bad. If the firm's projects are bad, the auditor again weighs the costs and benefits from pursuing an action $a_{2} \in\left\{a^{b}, a^{g}\right\}$. If he chooses to ignore his private information (i.e. take action $a^{g}$ ), his payoffs are the same as in the first stage. The main distinction from the first stage emerges if he decides to reveal the information. Since when the client is bad, the auditor enters the second stage only if he has misrepresented the client performance in the first stage, the disclosure of the information implies that the auditor misbehaved in the prior period. As a result, in addition to incurring switching costs, as in the previous scenario, he pays the penalty $R$. The corresponding decision problem is illustrated in Figure 4.

Figure 4. Decision tree with a slippery slope.

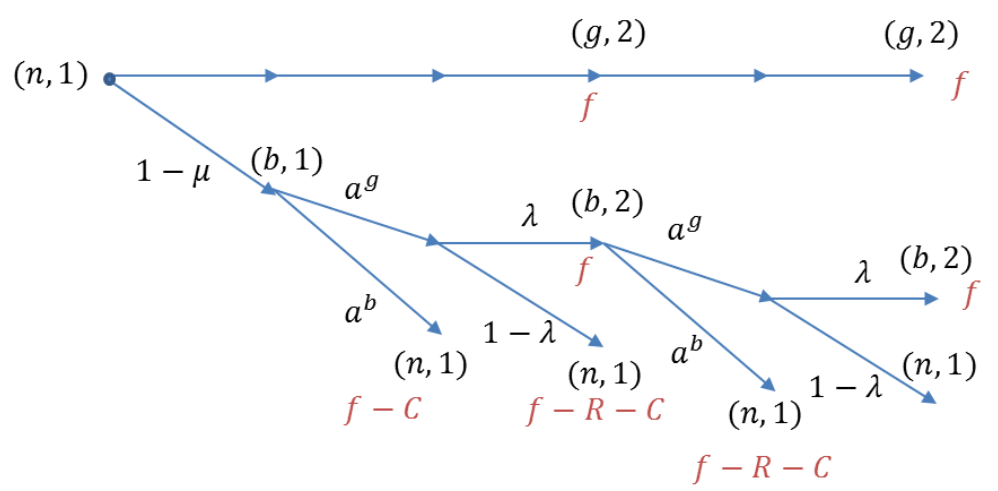


For any state the auditor reached in the second stage, there is a decision problem that continues in the third stage. If the auditor switched in the second stage, he starts a new client engagement and transitions to state $(n, 1)$. If the auditor continues auditing the same client, then he faces the same situation he has faced at stage two. If the client is good, the auditor continues his relationship with a client and receives audit fees. If the client is bad, the auditor faces the same dilemma: to expose the client, which is equivalent to disclosing his own past choices, or to certify the client's report and risk being penalized. Thus, the auditor stays in the same state as in stage two. Next, I summarize the payoffs and transition probabilities in the decision problem.

In the first stage of an engagement $(\tau=1)$, the auditor's payoffs and transitions are as follows:

- $\pi_{t}((n, 1))=0, p((g, 1) \mid(n, 1))=\mu, p((b, 1) \mid(n, 1))=1-\mu$.

- $\pi_{t}((g, 1))=f, p((g, 2) \mid(g, 1))=1$, if the firm is good. The auditor transitions to state $(g, 2)$ with probability 1 .

- $\pi_{t}\left((b, 1), a^{b}\right)=f-C, p\left((n, 1) \mid(b, 1), a^{b}\right)=1$, if the firm is bad and the auditor chooses to reveal the information. The auditor transitions to state $(n, 1)$ with probability 1.

- $\left.\pi_{t}\left((b, 1), a^{g}\right)=f-R-C, p\left((n, 1) \mid(b, 1), a^{g}\right)\right)=1-\lambda$, if the firm is bad, the auditor chooses to certify the firm's report, and the project fails. The auditor transitions to state $(n, 1)$ with probability $(1-\lambda)$. 
- $\pi_{t}\left((b, 1), a^{g}\right)=f, p\left((b, 2) \mid(b, 1), a^{g}\right)=\lambda$, if the firm is bad, the auditor chooses to certify the firm's report, and the project generates cash flows. The auditor transitions to state $(b, 2)$ with probability $\lambda$.

In the second stage of an engagement $(\tau=2)$, the auditor's payoffs and transitions are given by:

- $\pi_{t+1}((g, 2))=f, p((g, 2) \mid(g, 2))=1$, if the firm is good. The auditor stays in state $(g, 2)$.

- $\pi_{t+1}\left((b, 2), a^{b}\right)=f-R-C, p\left((n, 1) \mid(b, 2), a^{b}\right)=1$, if the firm is bad and the auditor chooses to reveal the information. The auditor transitions to state $(n, 1)$ with probability 1.

- $\left.\pi_{t+1}\left((b, 2), a^{g}\right)=f-R-C, p\left((n, 1) \mid(b, 2), a^{g}\right)\right)=1-\lambda$, if the firm is bad, the auditor chooses to certify the firm's report, and the project fails. The auditor transitions to state $(n, 1)$ with probability 1 .

- $\pi_{t+1}\left((b, 2), a^{g}\right)=f, p\left((b, 2) \mid(b, 2), a^{g}\right)=\lambda$, if the firm is bad, the auditor chooses to certify the firm's report, and the project generates cash flows. The auditor stays in state $(b, 2)$.

The payoffs and transition probabilities among states depend only on the current state, therefore satisfy Markov property, as in the benchmark model.

The Bellman equations characterized for each state of the auditor's decision problem:

$$
\begin{gathered}
V(n, 1)=\mu V(g, 1)+(1-\mu) V(b, 1) \\
V(g, 1)=f+\delta V(g, 2)
\end{gathered}
$$




$$
\begin{gathered}
V(b, 1)=\max \{f-C+\delta V(n, 1), f+(1-\lambda)(-R-C+\delta V(n, 1))+\lambda \delta V(b, 2)\} \\
V(g, 2)=f+\delta V(g, 2) \\
V(b, 2)=\max \{f-C-R+\delta V(n, 1), f+(1-\lambda)(-R-C+\delta V(n, 1))+\lambda \delta V(b, 2)\}
\end{gathered}
$$

Equations (11) and (13) represent the auditor's value function when the firm is good. Essentially, he completes the audit, receives the audit fee and starts auditing another good project. Equations (12) and (14) describe the auditor's tradeoff when he discovers that the client is bad. Equation (10) is the auditor's expected utility at the beginning of the first stage of the engagement before he observes the firm quality.

Proposition 4 establishes the auditor's optimal strategy in this framework.

Proposition 4. The optimal strategy of the auditor is to disclose the bad quality of the client's project if $C \leq C^{\prime}$, where $C^{\prime}=\frac{(1-\lambda) R(1-(1-\mu) \delta)}{\lambda(1-\delta)}$. If $C \geq C^{\prime}$, the auditor accommodates the client by certifying her report in the first stage of the engagement and continues to accommodate the client in each of the next periods until one of the projects fails.

Proof.

Given the auditor reached state $(b, 2)$, the auditor's dominant strategy is to accommodate the client by certifying her report, since

$$
\begin{gathered}
f+(1-\lambda)(-R-C+\delta V(n, 1))+\delta \lambda V(b, 2)>f-C+\delta V(n, 1) \\
>f-C-R+\delta V(n, 1) .
\end{gathered}
$$

This means that once the auditor reaches state $(b, 2)$, he continues to repeatedly take action $a^{g}$, which returns him back to $(b, 2)$ until one of the audited projects fails with probability $1-\lambda$. When this happens, he incurs the costs $C+R$ and transitions to state 
$(s, 1)$. Intuitively, this means that if the auditor misrepresents the client's project performance once, he starts down a slippery slope and has to continue misrepresenting the client's performance until he gets exposed. The net discounted utility of the auditor at $(b, 1)$ can be expressed as:

$$
\begin{aligned}
V(b, 1)=f+ & (1-\lambda)(-R-C+\delta V(n, 1))+\delta \lambda V(b, 2) \\
& =f+(1-\lambda)(-R-C+\delta V(n, 1)) \\
& +\delta \lambda(f+(1-\lambda)(-R-C+\delta V(n, 1)) \\
& +\delta \lambda(f+(1-\lambda)(-R-C+\delta V(n, 1))+\cdots))= \\
& =\frac{f}{1-\delta \lambda}+\frac{(1-\lambda)(-R-C+\delta V(n, 1))}{1-\delta \lambda} .
\end{aligned}
$$

Thus, the expected utility of the auditor at state $(b, 1)$ can be represented as a sum of three components. The first component, $\frac{f}{1-\delta \lambda}$, is the discounted stream of audit fees that he expects to receive, if the firm's project generates positive cash flows in subsequent periods. The second component, $\frac{(1-\lambda)(-R-C)}{1-\delta \lambda}$, is the expected damage incurred if one of the firm's projects fails. Since the auditor does not know with certainty in which of the periods he may get exposed, the chance of this event happening is aggregated over the infinity. The third component, $\frac{(1-\lambda) \delta V(n, 1)}{1-\delta \lambda}$, is the auditor's expected utility from all subsequent engagements.

State $(g, 2)$ is absorbing and there is no decision making in it. When the auditor achieves this state, he expects to receive audit fees without incurring any additional costs. The expected utility in this case can be expressed as: 


$$
V(g, 1)=V(g, 2)=\sum_{j=0}^{\infty} \delta^{j} f=\frac{f}{1-\delta}
$$

Next, I analyze the case where the auditor optimally chooses to disclose the quality of his client at the first stage of the engagement, and determine the auditor's expected utility at state $(n, 1)$ (the scenario when it is optimal for the auditor to accommodate the client is examined in a similar fashion in the appendix).

Given the strategy, the utility function $V(n, 1)$ satisfies:

$$
\begin{gathered}
V(n, 1)=\mu V(g, 1)+V(b, 1)=\frac{\mu f}{1-\delta}+(1-\mu)(f-C+\delta V(n, 1)) ; \\
V(n, 1)=\frac{f}{1-\delta}-\frac{(1-\mu) C}{1-(1-\mu) \delta} .
\end{gathered}
$$

This value function is the sum of the discounted future audit fees subtracted by the expected damages incurred whenever a bad client is dropped.

The policy improvement criterion for the switching being an optimal strategy at state $(b, 1)$ then can be expressed by:

$$
f-C+\delta V(n, 1) \geq \frac{f}{1-\delta \lambda}+\frac{(1-\lambda)(-R-C+\delta V(n, 1))}{1-\delta \lambda} .
$$

Inserting the expression for $V(n, 1)$ into the inequality yields:

$$
\begin{aligned}
f-C+\delta\left(\frac{f}{1-\delta}-\frac{(1-\mu) C}{1-(1-\mu) \delta}\right) \\
\geq \frac{f}{1-\delta \lambda}+\frac{(1-\lambda)(-R)}{1-\delta \lambda}+\frac{(1-\lambda)(-C)}{1-\delta \lambda} \\
+\frac{(1-\lambda) \delta}{1-\delta \lambda}\left(\frac{f}{1-\delta}-\frac{(1-\mu) C}{1-(1-\mu) \delta}\right) .
\end{aligned}
$$


In the infinite-horizon decision problem, the audit fees are the same across the two strategies. Therefore, I obtain the following condition on the costs the auditor expects in each of the scenarios:

$$
-C-\delta \frac{(1-\mu) C}{1-(1-\mu) \delta} \geq \frac{(1-\lambda)(-R)}{1-\delta \lambda}+\frac{(1-\lambda)(-C)}{1-\delta \lambda}+\frac{(1-\lambda) \delta}{1-\delta \lambda} \frac{(1-\mu)(-C)}{1-(1-\mu) \delta}
$$

The expression, $\delta \frac{(1-\mu) C}{1-(1-\mu) \delta}$, is a delayed discounted sum of the switching costs paid each time a bad client is dropped. The two terms, $\frac{(1-\lambda)(-R)}{1-\delta \lambda}$ and $\frac{(1-\lambda)(-C)}{1-\delta \lambda}$, are the costs expected to be incurred when the auditor's current client fails. Since the auditor does not know with certainty when this will happen, he expects it to happen with some probability in each of the periods of his planning horizon.

Next, I rearrange the components of the inequality to group the anticipated costs from all subsequent engagements together:

$$
-C-\frac{\delta(1-\mu) C}{1-(1-\mu) \delta} \frac{(1-\delta) \lambda}{1-\delta \lambda} \geq \frac{(1-\lambda)(-R)}{1-\delta \lambda}+\frac{(1-\lambda)(-C)}{1-\delta \lambda} .
$$

The left-hand side of the inequality represents the auditor's immediate switching costs and the aggregated costs from subsequent engagements generated by an earlier termination of the current engagement. The right-hand side represents the expected costs that will be paid when the current client fails. This inequality sheds light both on the role of the probability $\mu$ of getting a good client and a bad project success rate $\lambda$.

Because an auditor, who finds a good client, expects to keep him for an indefinitely long time and enjoy a stream of audit fees without additional risks, a higher chance of getting a good client significantly increases his expected utility from returning to the external market. Therefore, if the pool of potential clients contains mostly good firms (i.e. $\mu$ is 
close to 1), the auditor estimates the costs from an earlier termination of an engagement, $\frac{\delta(1-\mu) C}{1-(1-\mu) \delta} \frac{(1-\delta) \lambda}{1-\delta \lambda}$, to be close to 0. In other words, if the external market is sufficiently good, the auditor has stronger incentives to drop a bad client. If the pool of potential clients contains mostly bad firms (i.e. $\mu$ is close to 0 ), then the auditor expects to drop almost any firm he gets. In this situation, he has less to gain by dropping the current client, even if he believes that the firm may fail in the near future.

When the project survival rate $\lambda$ is high, the expected time to failure is very large. Hence, the auditor chooses between incurring immediate switching costs and paying a penalty for a failed audit in the distant future. If $\lambda$ is low, the expected time to failure is likewise low and then the auditor expects to be exposed very soon. Therefore, he chooses between terminating the engagement voluntarily or being penalized and forced to switch anyway. Finally, I derive the threshold level of the switching costs $C^{\prime}$ :

$$
\begin{gathered}
(1-\lambda) R=\lambda(1-\delta) C^{\prime}\left[1+\frac{(1-\mu) \delta}{1-(1-\mu) \delta}\right]=\frac{\lambda(1-\delta) C^{\prime}}{1-(1-\mu) \delta} \\
C \leq C^{\prime}=\frac{(1-\lambda) R(1-(1-\mu) \delta)}{\lambda(1-\delta)}
\end{gathered}
$$

The slippery slope model demonstrates that when a firm produces projects of a uniform quality, an auditor becomes reluctant to disclose the true quality of the projects if he has already misrepresented the client's performance once. In fact, the auditor continues to accommodate the problematic client by certifying her reports in order to avoid the same costs that forced him to start down the slippery slope in the first place. Furthermore, he must also cover his previous wrongdoings as well which gives him even more incentives 
to misrepresent the client's performance. This feature of the model echoes findings in Corona and Randrawa (2010).

The model also helps to understand the auditor's incentives to disclose the negative information about the client when it is first discovered. The auditor maximizes over two choices as in the previous setting: to keep the client or to switch. However, now he anticipates that he may go down the slippery slope if he decides to keep a bad client. This makes him unambiguously prefer to audit good firms since then he can enjoy the stream of audit fees without taking additional risks. Therefore, the chances of getting a good replacement client becomes an important factor in the auditor's decision making.

By examining the auditor's dilemma in Proposition 4, I delineated two forces driving the auditor's decision-making in the slippery slope model. First, if the auditor estimates his chances to find a good client as low and his switching costs are high, then he has more incentives to provide the client with favorable reports in order to maintain the engagement. On the other hand, if the auditor's pool of potential clients is good, he anticipates that, after dropping a bad firm, he will find a good replacement that he can keep for an indefinitely long time and enjoy a stream of audit fees. Second, if projects of the bad firm have a high failure rate, then the prospect of being penalized disciplines the auditor and he acts with more independence. In particular, if the bad client's chance of surviving is close to 0 , then the auditor never chooses to accommodate her. If the failure rate is sufficiently low, then good and bad firms become almost equally attractive from the auditor's perspective, and the auditor prefers to certify the bad client's report to avoid the switching costs. 


\subsection{Slippery slope model with mandatory rotation.}

In the previous subsection, I presented a setting that illustrated two forces disciplining an auditor. Both are functions of the length of the auditor's engagement.

The first force is the quality of the pool of the auditor's potential clients. If the auditor estimates that his chances of getting a good replacement client are high, he will be more willing to drop the current client. Furthermore, the longer he can keep a new good client, the higher the value of returning to the external market for replacement clients.

The second force is the auditor's expectations of a bad client failure. The auditor knows that if he misrepresents the client's performance once, he must cover this wrongdoing in all subsequent periods until one of the client's projects fails. Therefore, if a client's projects are likely to fail, then the auditor expects to be exposed and be forced to pay a penalty relatively soon.

Since mandatory rotation truncates the auditor's current and future engagements, the disciplining effect of these two forces may partially vanish, which in turn may lead to impaired auditor independence. In the benchmark model, I demonstrated that the effect of mandatory rotation is positive. In the rest of the paper I will resolve these disparate results by comparing auditor incentives across the two regulatory regimes and identifying the reasons why the result in the slippery slope model may contradict the initial finding. I now formally analyze the effect of mandatory rotation in a slippery slope setting. As in the benchmark model, in this setting the auditor must resign after two periods of an engagement. The auditor starts an engagement from the state $(n, 1)$, in which he has no information about the client. Then, after learning the firm's type, he either transitions to 
state $(g, 1)$ or $(b, 1)$, with corresponding probabilities $\mu$ and $(1-\mu)$ respectively. If the auditor observes that his client is bad (i.e. he transitions to state $(b, 1))$, he may choose to disclose the information and terminate the engagement (action $a^{b}$ ) or to ignore the information and keep the client (action $a^{g}$ ). In the latter case, he will be exposed with probability $1-\lambda$, if the project fails; otherwise he proceeds into the second stage of the engagement.

In the second stage, the auditor already knows the firm's type. Hence, depending on the type, he transitions either to $(g, 2)$ or $(b, 2)$ with probability 1 . If the auditor's state is $(b, 2)$, then he again faces a dilemma; whether to disclose the bad project quality to the market or ignore it and certify the client's report. Since the auditor enters the second stage of an engagement with a bad client only if he has certified a biased report in the preceding period, if he discloses the bad project, the market infers that he has misbehaved at some point in the past. Therefore, as in the slippery slope model, if he discloses the information, in addition to incurring switching costs, he pays the penalty $R$. Furthermore, in the mandatory rotation regime, even if he certifies the client's report, he must rotate and incur the switching costs. In either case, in the following period the auditor starts a new engagement; hence he returns to state $(n, 1)$ with probability 1 . The auditor's decision tree is illustrated in Figure 5. 
Figure 5. Decision tree in the mandatory rotation case with a slippery slope.

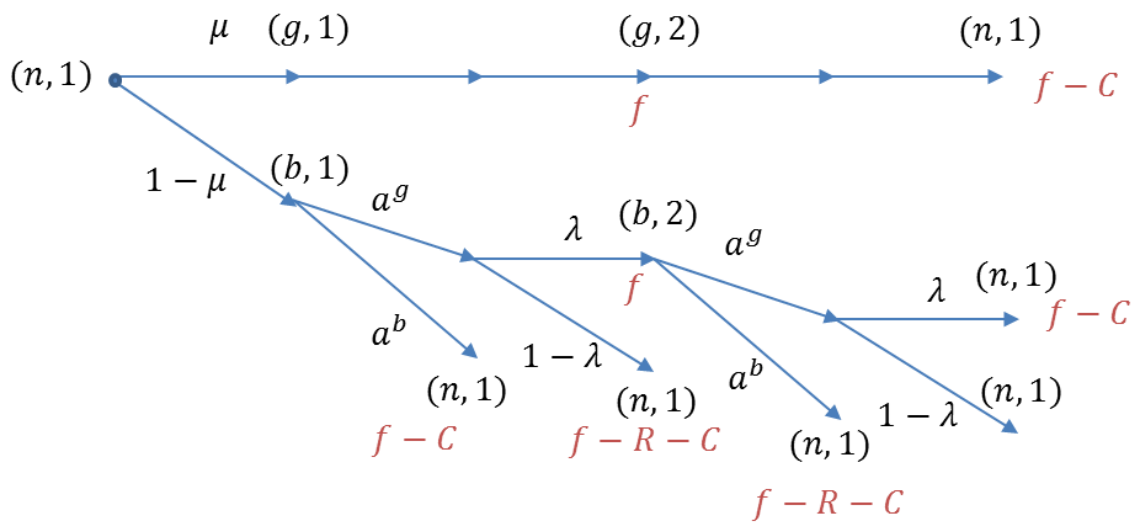

In the first stage of an engagement $(\tau=1)$, the auditor's payoffs and transitions are the same as in the slippery slope model:

- $\quad \pi_{t}((g, 1))=f, p((g, 2) \mid(g, 1))=1$, if the firm is good. The auditor transitions to state $(g, 2)$ with probability 1 .

- $\pi_{t}\left((b, 1), a^{b}\right)=f-C, p\left((n, 1) \mid(b, 1), a^{b}\right)=1$, if the firm is bad, and the auditor chooses to reveal the information.

- $\left.\quad \pi_{t}\left((b, 1), a^{g}\right)=f-R-C, p\left((n, 1) \mid(b, 1), a^{g}\right)\right)=1-\lambda$, if the firm is bad, the auditor chooses to certify the firm's report, and the project fails. The auditor transitions to state $(n, 1)$ with probability $1-\lambda$.

- $\quad \pi_{t}\left((b, 1), a^{g}\right)=f, p\left((b, 2) \mid(b, 1), a^{g}\right)=\lambda$, if the firm is bad, the auditor chooses to certify the firm's report, and the project generates cash flows. The auditor transitions to state $(b, 2)$ with probability $\lambda$.

In the second stage of an engagement $(\tau=2)$, the auditor's payoffs are adjusted for the rotation costs and the auditor transitions to state $(n, 1)$ from each of the states: 
- $\quad \pi_{t+1}((g, 2))=f-C, p((n, 1) \mid(g, 2))=1$, if the firm is good. The auditor transitions to state $(n, 1)$ with probability 1 .

- $\quad \pi_{t+1}\left((b, 2), a^{b}\right)=f-R-C, p\left((n, 1) \mid(b, 2), a^{b}\right)=1$, if the project is bad and the auditor chooses to reveal the information. The auditor transitions to state $(n, 1)$ with probability 1 .

- $\left.\quad \pi_{t+1}\left((b, 2), a^{g}\right)=f-R-C, p\left((n, 1) \mid(b, 1), a^{g}\right)\right)=1$, if the firm is bad, the auditor chooses to certify the firm's report, and the project fails. The auditor transitions to state $(n, 1)$ with probability 1 .

- $\quad \pi_{t+1}\left((b, 2), a^{g}\right)=f-C, p\left((n, 1) \mid(b, 1), a^{g}\right)=1$, if the firm is bad, the auditor chooses to certify the firm's report, and the project generates cash flows. The auditor transitions to state $(n, 1)$ with probability 1 .

The payoffs and transition probabilities among states depend only on the current state and satisfy Markov property. Next, I write out the Bellman equation characterized for each state of the auditor's decision problem:

$$
\begin{gathered}
V(n, 1)=\mu V(g, 1)+(1-\mu) V(b, 1) \\
V(g, 1)=f+\delta V(g, 2) \\
V(b, 1)=\max \{f-C+\delta V(n, 1), f+(1-\lambda)(-R-C+\delta V(n, 1))+\lambda \delta V(b, 2)\} \\
V(g, 2)=f-C+\delta V(n, 1) \\
V(b, 2)=\max \{f-C-R+\delta V(n, 1), f+(1-\lambda)(-R)-C+\delta V(n, 1)\}
\end{gathered}
$$

Equations (16) and (18) represent the auditor's value function when the firm is good. Equations (17) and (19) describe the auditor's tradeoff when the client is bad. Equation 
(15) is the auditor's expected utility at the beginning of the first stage of the engagement before he observes the firm quality.

Proposition 5 establishes the conditions determining the auditor's optimal strategy.

Proposition 5. The optimal strategy of the auditor is to disclose the bad quality of the client's project, if $C \leq C^{\prime \prime}$, where $C^{\prime \prime}=\frac{R(1-\lambda)(1+\delta \lambda)}{\lambda}(1+\mu \delta)$. If $C \geq C^{\prime \prime}$, the auditor accommodates the client by certifying her report in both stages of the engagement.

Proof.

I start by analyzing strategies at state $(b, 2)$, which is before the rotation. The auditor will always choose to keep the client and certify her report, which is demonstrated by:

$$
f-(1-\lambda) R-C+\delta V(n, 1)>f-C-R+\delta V(n, 1) .
$$

Notice that even if $\lambda$ is close to 0 (i.e. the auditor gets exposed almost with certainty), he will choose to take the risks and certify the bad client's report instead of voluntarily confessing his past choices by revealing the project quality.

As a result, the auditor's expected utility $V(b, 2)$ is equivalent to $f-(1-\lambda) R-C+$ $\delta V(n, 1)$

I assume that $a_{1}=a^{b}$ is the auditor's optimal strategy and find the value for $V(n, 1)$. The scenario when the auditor chooses $a_{1}=a^{g}$ is examined in a similar fashion in the appendix.

$$
\begin{gathered}
V(n, 1)=\mu V(g, 1)+(1-\mu) V(b, 1) \\
=\mu\left(f+\delta(f-C)+\delta^{2} V(n, 1)\right)+(1-\mu)(f-C+\delta V(n, 1)) ; \\
V(n, 1)\left(1-(1-\mu) \delta-\delta^{2} \mu\right)=f+\mu \delta f-C(\mu \delta+1-\mu) ;
\end{gathered}
$$




$$
V(n, 1)=\frac{f}{1-\delta}-\frac{C(\mu \delta+1-\mu)}{1-(1-\mu) \delta-\delta^{2} \mu}
$$

The auditor's value function at the beginning of any engagement is the discounted sum of the audit fees less the switching costs expected to be paid in the event of required rotation and voluntary termination when the client is bad.

The policy improvement criterion for the auditor at state $(b, 1)$ is determined by:

$$
\begin{gathered}
f-C+\delta V(n, 1) \geq f+(1-\lambda)(-R-C+\delta V(n, 1))+\delta \lambda V(b, 2) \\
f-C+\delta V(n, 1) \\
\geq f+(1-\lambda)(-R-C+\delta V(n, 1)) \\
+\delta \lambda(f-(1-\lambda) R-C+\delta V(n, 1)) \\
f-C+\delta V(n, 1) \quad \\
\geq f(1+\delta \lambda)+(-R-C)(1-\lambda)(1+\delta \lambda)-C \delta \lambda^{2} \\
+\delta V(n, 1)(1-\lambda+\delta \lambda) .
\end{gathered}
$$

In this setting the auditor's engagement lasts at most two periods, as opposed to the previous scenario where it lasts until a bad client fails. As a result, the expected costs of keeping a bad client, $(-R-C)(1-\lambda)(1+\delta \lambda)$, in the mandatory rotation regime are lower than the expected costs, $\frac{(1-\lambda)(-R)}{1-\delta \lambda}+\frac{(1-\lambda)(-C)}{1-\delta \lambda}$, in the no-rotation regime. The terms of the inequality containing $V(n, 1)$ represent the auditor's expected utility from auditing future clients. Collecting these terms on the left-hand side of the inequality yields:

$$
f-C+\delta V(n, 1)(\lambda-\delta \lambda) \geq f(1+\delta \lambda)+(-R-C)(1-\lambda)(1+\delta \lambda)-C \delta \lambda^{2}
$$

The resulting term $\delta V(n, 1)(\lambda-\delta \lambda)$ represents the difference between the auditor's expected utilities from auditing future clients across the two strategies. The auditor may 
get exposed in the current period or in the following period. Consequently, the damages the auditor incurs are summarized by:

$$
(-R-C)(1-\lambda)+\delta \lambda(-R-C)(1-\lambda)=(-R-C)(1-\lambda)(1+\delta \lambda) .
$$

The auditor has to pay switching costs in the second stage of the engagement even if both of the client's projects generated cash flows. These switching costs are reflected by the term $-C \delta \lambda^{2}$.

Inserting the expression for $V(n, 1)$ results in:

$$
\begin{gathered}
f-C+\delta \lambda(1-\delta)\left[\frac{f}{1-\delta}-\frac{C(\mu \delta+1-\mu)}{1-(1-\mu) \delta-\delta^{2} \mu}\right] \\
\geq f(1+\delta \lambda)+(-R-C)(1-\lambda)(1+\delta \lambda)-C \delta \lambda^{2} ; \\
f-C+\delta \lambda f-\frac{\delta \lambda C(\mu \delta+1-\mu)}{1+\mu \delta} \geq f(1+\delta \lambda)+(-R-C)(1-\lambda)(1+\delta \lambda)-C \delta \lambda^{2} .
\end{gathered}
$$

Since the audit fees are the same across the two strategies, only the costs expected to be incurred drive his decision at $(b, 1)$ :

$$
-C-\frac{\delta \lambda C(\mu \delta+1-\mu)}{1+\mu \delta} \geq(-R-C)(1-\lambda)(1+\delta \lambda)-C \delta \lambda^{2} .
$$

As in the no-rotation regime, the auditor chooses between switching immediately after he observes the client's type or delaying the switch.

There are two substantial differences between the regimes. First, the length of the delay is different. In the mandatory rotation regime, the auditor may switch because of the client's failure in the first period and incur the costs $(-R-C)(1-\lambda)$. If the client survives into the second period, the auditor has to pay either $(-R-C)(1-\lambda) \delta \lambda$ if the client fails, or $C \delta \lambda^{2}$ even if the client's project generates cash flows due to the mandatory rotation. In 
the regime without rotation the auditor has to switch only if the client fails at some undetermined point in the future. Second, the auditor's expectation of costs generated by all subsequent engagements has shifted. He can no longer keep a good firm indefinitely since the audit terms are limited. Next, I derive a reduced form of the inequality which better explains the auditor's anticipated costs:

$$
\begin{gathered}
-C-\frac{\delta \lambda C(\mu \delta+1-\mu)}{1+\mu \delta}+C(1-\lambda)(1+\delta \lambda)+C \delta \lambda^{2} \geq(-R)(1-\lambda)(1+\delta \lambda) \\
-\frac{C}{1+\mu \delta} \geq-\frac{R(1-\lambda)(1+\delta \lambda)}{\lambda} .
\end{gathered}
$$

The right-hand side of the inequality, $R(1-\lambda)(1+\delta \lambda) / \lambda$, represents the penalties the auditor expects to pay if his client fails in one of the periods of the engagement. Similar to the mandatory rotation case in the benchmark model, the left-hand side, $-\frac{C}{1+\mu \delta}$, can be represented as a discounted sum of the expected costs and costs savings, $\sum_{j=0}^{\infty}(-1)^{j} \mu^{j} \delta^{j}(-C)$, via a geometric series expansion. Intuitively, if the auditor terminates the engagement earlier, he incurs immediate switching costs but simultaneously delays the next required rotation by one period. If each of the auditor's future clients is good, the sequence of delays will generate a positive value in perpetuity. This yields the following threshold level of switching costs $C^{\prime \prime}$ :

$$
C \leq C^{\prime \prime}=\frac{R(1-\lambda)(1+\delta \lambda)(1+\mu \delta)}{\lambda}
$$

Proposition 5 highlights an important distinction between how the rotation requirement affects the benchmark and the slippery slope models. In the benchmark model, the auditor chooses to disclose the bad quality of the client's project in the last period of the 
engagement even if he misrepresented the client's performance earlier. However, in the slippery slope model, if the auditor reveals the bad project quality at the end of the engagement, it implies that he ignored his bad information and certified the report in the previous period. Therefore, the auditor chooses to accommodate the client again since he prefers to take the risk of being exposed and incurring a penalty instead of being penalized with certainty.

Next, I compare the auditor's incentives to misrepresent the firm's performance across the two regimes in the slippery slope model. As in the benchmark model, I calculate the difference between the threshold levels of switching costs. I show that if the model parameters lie in certain regions, the auditor has more incentives to remain independent in the regime without mandatory rotation.

\section{Proposition 6.}

1) The threshold level $C^{\prime \prime}$ in the regime with mandatory rotation is lower than the threshold level $C^{\prime}$ in the regime without mandatory rotation if and only if parameters $\delta, \mu$, and $\lambda$ belong to the regions specified in (20), (21), and (22):

$$
\begin{gathered}
\left(\lambda<\frac{\delta \mu}{(1-\delta)(1+\delta \mu)}\right) \&\left(\mu<\frac{1-\delta}{\delta^{2}}\right) \&\left(\delta \in\left(\frac{1}{2}(\sqrt{5}-1) ; 1\right)\right) \\
\left(\lambda<\frac{\delta \mu}{(1-\delta)(1+\delta \mu)}\right) \&\left(\delta \in\left(0 ; \frac{1}{2}(\sqrt{5}-1)\right)\right) \&(\forall \mu \in(0,1)) \\
\left(\mu \geq \frac{1-\delta}{\delta^{2}}\right) \&\left(\delta \in\left(\frac{1}{2}(\sqrt{5}-1) ; 1\right)\right) \&(\forall \lambda \in(0,1))
\end{gathered}
$$

If the auditor's actual switching costs, $C$, lie in the interval $\left(C^{\prime \prime}, C^{\prime}\right)$, then mandatory rotation impairs auditor independence. If the actual switching costs lie 
outside the interval, then the auditor reporting strategy is not affected by the regime change.

2) The threshold level $C^{\prime \prime}$ in the regime with mandatory rotation is higher than the threshold level $C^{\prime}$ in the regime without mandatory rotation if and only if parameters $\delta, \mu$, and $\lambda$ belong to the regions specified in (23) and (24) (i.e. lie outside the regions (20), (21), and (22)).

$$
\begin{gathered}
\left(\lambda>\frac{\delta \mu}{(1-\delta)(1+\delta \mu)}\right) \&(\forall \mu \in(0,1)) \&\left(\delta \in\left(0 ; \frac{1}{2}(\sqrt{5}-1)\right)\right) \\
\left(\lambda>\frac{\delta \mu}{(1-\delta)(1+\delta \mu)}\right) \&\left(\mu<\frac{1-\delta}{\delta^{2}}\right) \&\left(\delta \in\left(\frac{1}{2}(\sqrt{5}-1) ; 1\right)\right)
\end{gathered}
$$

If the auditor's actual switching costs lie in the interval $\left(C^{\prime}, C^{\prime \prime}\right)$, the auditor chooses to expose the client when he first learns that the client's project is bad. If they lie outside the interval, then mandatory rotation has no effect on auditor independence.

Proof.

First, I compare the auditor incentives to misrepresent the client's performance across the two regimes. As in the benchmark model, I find the difference between $C^{\prime \prime}$ and $C^{\prime}$ :

$$
\begin{gathered}
C^{\prime \prime}-C^{\prime}=\frac{R(1-\lambda)(1+\delta \lambda)(1+\mu \delta)}{\lambda}-\frac{(1-\lambda) R(1-(1-\mu) \delta)}{\lambda(1-\delta)} \\
=\frac{R \delta(1-\lambda)((1-\delta) \lambda(1+\delta \mu)-\delta \mu)}{(1-\delta) \lambda}
\end{gathered}
$$

where $(1-\delta) \lambda(1+\delta \mu)-\delta \mu$ determines the sign of the difference. 


$$
(1-\delta) \lambda(1+\delta \mu)-\delta \mu=\left(\lambda-\frac{\delta \mu}{(1-\delta)(1+\delta \mu)}\right)(1-\delta)(1+\delta \mu)
$$

Therefore, $C^{\prime \prime}-C^{\prime}$ is less than 0 , if and only if:

$$
\lambda<\frac{\delta \mu}{(1-\delta)(1+\delta \mu)}, \text { where } \lambda, \mu, \delta \in(0,1) .
$$

This condition shows that if the bad project success rate $\lambda$ is lower than some level, then the auditor may prefer to keep the client in the mandatory rotation regime and terminate the engagement in the no-rotation regime. This level is determined by an increasing function of $\mu$, namely $\frac{\delta \mu}{(1-\delta)(1+\delta \mu)}$.

As demonstrated by Proposition 6, low $\lambda$ and high $\mu$ discipline the auditor. Truncation of the auditor engagement leads to a partial dissolution of the disciplining effect. By comparing $\lambda$ and $\frac{\delta \mu}{(1-\delta)(1+\delta \mu)}$ via the inequality (25), one can determine the levels of $\lambda$ and $\mu$ that lead to mandatory rotation having a negative effect on auditor's incentives.

Since $\frac{\delta \mu}{(1-\delta)(1+\delta \mu)}$ could be larger than 1, I further analyze the condition in (25) by breaking it down into the following system of inequalities:

1. $\left(\lambda<\frac{\delta \mu}{(1-\delta)(1+\delta \mu)}\right) \&\left(\frac{\delta \mu}{(1-\delta)(1+\delta \mu)}<1\right)$

2. $\frac{\delta \mu}{(1-\delta)(1+\delta \mu)} \geq 1$

The first condition demonstrates the case when the auditor's expectations of the external market opportunities are relatively low. Under these circumstances, only rather low success rates of $\lambda$ generate a strong enough disciplining effect to make an auditor act with less independence in the mandatory rotation regime. 
It is useful to notice that:

$$
\frac{\delta \mu}{(1-\delta)(1+\delta \mu)}<1 \Leftrightarrow\left(\mu<\frac{1-\delta}{\delta^{2}}\right) \&\left(\frac{1-\delta}{\delta^{2}}<1\right) \text { or }(\mu<1) \&\left(\frac{1-\delta}{\delta^{2}}>1\right)
$$

Thus, the first inequality also breaks down into the following subcomponents:

1a. $\left(\lambda<\frac{\delta \mu}{(1-\delta)(1+\delta \mu)}\right) \&\left(\mu<\frac{1-\delta}{\delta^{2}}\right) \&\left(\frac{1-\delta}{\delta^{2}}<1\right)$.

1b. $\left(\lambda<\frac{\delta \mu}{(1-\delta)(1+\delta \mu)}\right) \&(\forall \mu \in(0,1)) \&\left(\frac{1-\delta}{\delta^{2}} \geq 1\right)$.

where $\frac{1-\delta}{\delta^{2}}<1$ is valid as long as $\delta \in\left(\frac{1}{2}(\sqrt{5}-1) ; 1\right)$, and reverses if $\delta \in$ $\left(0 ; \frac{1}{2}(\sqrt{5}-1)\right)$

Therefore, I obtain:
1a. $\left(\lambda<\frac{\delta \mu}{(1-\delta)(1+\delta \mu)}\right) \&\left(\mu<\frac{1-\delta}{\delta^{2}}\right) \&\left(\delta \in\left(\frac{1}{2}(\sqrt{5}-1) ; 1\right)\right)$
1b. $\left(\lambda<\frac{\delta \mu}{(1-\delta)(1+\delta \mu)}\right) \&(\forall \mu \in(0,1)) \&\left(\delta \in\left(0 ; \frac{1}{2}(\sqrt{5}-1)\right)\right)$

The effect of the regulation is a function of the auditor's discount rate. To better understand the effect of the discount rate on auditor independence, notice that the auditor stops incurring costs when he finds a good client. As a result, if $\mu$ is low, the auditor expects that it may take longer to find such a client. A high $\delta$ means that even if the waiting time is very long, a forward-looking auditor plans for this event almost as if it is going to take place in the following period. As a result, in the regime without rotation, $\delta$ reinforces the disciplining effect produced by the value of returning to the external market. 
If the auditor is myopic, as represented by the inequality (1b), then even for high values of $\mu$, the auditor's anticipation of the external market opportunities is a weak form of discipline which is not affected by the regime change. Consequently, the truncation of the auditor's slippery slope reduces the auditor's independence in the mandatory rotation regime only for relatively lower $\lambda$.

If the auditor is forward looking, as in inequality (1a), the disciplining forces in the regime without rotation are reinforced by the high discount factor. As a result, the value of returning to the external market is low only if the quality of the pool, $\mu$, is low.

Next, I solve the second inequality for $\mu$ and derive the following decomposition:

2. $(\forall \lambda \in(0,1)) \&\left(\mu \geq \frac{1-\delta}{\delta^{2}}\right) \&\left(\delta \in\left(\frac{1}{2}(\sqrt{5}-1) ; 1\right)\right)$

The second inequality covers the case when the auditor's expectation of getting a good client is so high, that for any $\lambda$ the auditor finds it optimal to return to the external market in the regime without rotation and to keep the client in the mandatory rotation regime.

Following similar derivations, I find that $C^{\prime \prime}-C^{\prime}>0$ holds, if and only if:

$$
\begin{gathered}
\left(\lambda>\frac{\delta \mu}{(1-\delta)(1+\delta \mu)}\right) \&(\forall \mu \in(0,1)) \&\left(\delta \in\left(0 ; \frac{1}{2}(\sqrt{5}-1)\right)\right) \\
\left(\lambda>\frac{\delta \mu}{(1-\delta)(1+\delta \mu)}\right) \&\left(\mu<\frac{1-\delta}{\delta^{2}}\right) \&\left(\delta \in\left(\frac{1}{2}(\sqrt{5}-1) ; 1\right)\right)
\end{gathered}
$$

These regions demonstrate that mandatory rotation has a positive effect on auditor independence only when both the external market opportunities and the slippery slope do not have a significant disciplining effect (i.e. when $\lambda$ is high and the combination of $\delta$ and $\mu$ does not produce a high value of returning to the external market). 
As a result of Proposition 5 and Proposition 6, I obtain the following optimal strategies in the regimes with and without rotation:

$$
\begin{aligned}
& a_{1}=a^{b} \text {, if } C \leq C^{\prime} \text { and } a_{1}=a^{g} \text { if } C \geq C^{\prime} ; a_{2}=a^{g} . \\
& a_{1}=a^{b} \text {, if } C \leq C^{\prime \prime} \text { and } a_{1}=a^{g} \text { if } C \geq C^{\prime \prime} ; a_{2}=a^{g} .
\end{aligned}
$$

Thus, when the parameters belong to regions (20), (21), and (22), where $C^{\prime \prime}<C^{\prime}$, and $C \in\left(C^{\prime \prime}, C^{\prime}\right)$, the auditor chooses $a_{1}=a^{g}$ instead of $a^{b}$ while $a_{2}$ remains the same. This means that the auditor finds it optimal to certify reports of a bad client in all periods of his tenure when mandatory rotation is introduced.

Alternatively, if the parameters belong to the regions (23) and (24), where $C^{\prime}<C^{\prime \prime}$, and $C \in\left(C^{\prime}, C^{\prime \prime}\right)$, mandatory rotation will improve auditor independence since the auditor chooses $a_{1}=a^{b}$ instead of $a^{g}$

Proposition 6 demonstrates that under certain conditions, mandatory rotation has an adverse effect on auditor independence. Furthermore, analysis of these conditions illustrates that this adverse effect is a result of the dissolution of the economic forces that discipline the auditor. In particular, the auditor acts with less independence in the mandatory rotation regime when he either does not expect the external market to be attractive or he assesses the current client's survival rate as low.

In fact, mandatory rotation has a positive effect on auditor independence only for a limited range of parameters. As shown in (24) and (25), an auditor's independence improves only if the quality of his pool of potential clients is low, his actual switching costs lie in the region between the two thresholds, and bad firms have a high survival rate. 
Furthermore, Proposition 6 shows that after the auditor accommodates a bad client, even very high chances of being exposed and penalized cannot keep him from going down the slippery slope. In the mandatory rotation regime, the auditor will not disclose the quality of the last project; this result is opposite to that of the benchmark model. This means that mandatory rotation fails to break economic bonds between the auditor and the client, contrary to what regulators hope to achieve.

\section{Conclusion}

In this paper, I demonstrated that mandatory rotation does not necessarily make an auditor more independent. In fact, it may have an adverse effect on an auditor's incentives to disclose negative information about the client, contrary to the popular view. Specifically, I examined an auditor's decision problem under different regulatory regimes, with and without mandatory rotation, by deriving and comparing his optimal strategies across the regimes. I found that, in the presence of mandatory rotation, the term limits imposed on the length of an auditor's engagements lead to a partial dissolution of two important disciplining forces. First, the truncation of the auditor's current engagement provides the auditor with an opportunity to interrupt the course of bad actions if he has started down a slippery slope. Therefore, the initial decision to compromise his independence becomes comparatively less costly. Second, the term limits imposed on the auditor's future engagements decrease the value of returning to the external market by terminating an engagement with a problematic client. I showed that, through these two channels, mandatory rotation can impair auditor independence. 
To provide analytical tractability, I made some simplifying assumptions about the auditor, the firms, and the market. For instance, I assumed that a firm has to shut down after the auditor issues an unfavorable opinion on the client's report. In practice, the auditor's disclosure of a firm's issues does not necessarily result in firm closure or auditor resignation. As such, one possible extension would be to consider a situation in which the auditor keeps a client with some probability. Then, issuing an independent opinion becomes less costly since it does not inevitably trigger a client loss. Therefore, I expect the auditor to act with more independence in both regulatory regimes.

In this paper, I examined two polar situations: when the projects of one firm are completely independent of each other and when they are perfectly correlated. One further extension would be to assume a partial correlation among a firm's projects which would imply a limited persistence of the firm's performance. I would expect the basic insights to carry through to this case as well. For example, if the auditor anticipates the client's performance decline to be temporary, the auditor will be more willing to ignore some irregularities than in the slippery slope model since he believes that the slippery slope will not prevail. In this case, I expect the auditor to act with less independence in the regulatory regime without mandatory rotation, which will mitigate the negative effects of the regime change.

I employed a framework, in which the role of the market is limited to imposing a constant penalty on the auditor when his lack of independence becomes public. However, both the auditor's penalty and the switching costs may depend on the market's beliefs about how long the auditor's independence has been impaired, whether the auditor left the slippery 
slope by confessing his misbehavior, or whether the market expects his reporting strategy to improve in the future. One way to model the dynamics of market reactions is to make the payoffs a function of the market's perception of the auditor's commitment to being independent. This approach would bring additional insights into how the market's beliefs shape the auditor's optimal strategy. For instance, I would expect that if, based on the history of the auditor's actions, the market concludes that he has acted opportunistically, then no client will find it beneficial to hire such an auditor. Therefore, due to a dramatic increase in switching costs, the auditor must leave the market.

This study brings up novel evidence on the unintended consequences of the adoption of mandatory rotation. Although relaxing some of the assumptions would generate a model providing richer predictions, the main message of this paper will carry through. I specifically show that, in the presence of persistence in the firms' project characteristics and a dynamic decision environment, mandatory audit firm rotation may have a negative effect on auditor independence. This issue has not been discussed in the previous literature. Results of this study may encourage further research to reassess the impact of mandatory auditor rotation and stimulate debates on the elaboration of the policy change. 


\section{Bibliography.}

Bertsekas, D.P., (1995). Dynamic Programming and Optimal Control. Athena Scientific, Cambridge, MA.

Conference Board, (2003). Findings and Recommendations - Part 3: Auditing and Accounting. Conference Board SR 03-04. Conference Board, New York, NY.

Corona. C. \& Randhawa, R.S. (2010). The auditor's slippery slope: An analysis of Reputational Incentives. Management Science 56(6) 924-937.

General Accounting Office, (2003). Public Accounting Firms: Required Study on the Potential Effects of Mandatory Audit Firm Rotation. GAO 04-216. General Accounting Office, Washington, DC.

Gigler, F., \& Hemmer, T. (2008). On the welfare effects of allowing unlimited renegotiation in agency relationships. Economic Theory, 37(2), 243-265.

European Commission, (2015). Reform of the audit market. Available online: http://ec.europa.eu/finance/auditing/reform/index_en.htm.

Elitzur, R. \& Falk, H. (1996). Planned audit quality. Journal of Accounting and Public Policy, 15, 246-269.

International Ethics Standards Board for Accountants. (2013). Handbook of the Code of Ethics for Professional Accountants. IFAC: New York. Available at:

http://www.ifac.org/sites/default/files/publications/files/2013-IESBA-Handbook.pdf

Johnson, V., Khurana, I. K., \& Reynolds, J. K. (2002). Audit-firm tenure and the quality of financial reports. Contemporary Accounting Research, 19, 637-660.

Lu, T. \& Sivaramakrishnan, K. (2009). Mandatory auditor rotation: fresh look versus poor knowledge. Journal of Accounting and Public Policy, 28, 71-91.

Mathis J., McAndrews J., \& Rochet, J. (2009). Rating the raters: Are reputation concerns powerful enough to discipline rating agencies? Journal of Monetary Economics, 56, 657574.

Kanodia, C., Bushman, \& R. Dickhaut. J. (1989). Escalation errors and the sunk cost effect: An explanation based on reputation and information asymmetries. Journal of Accounting Research, 27(1), 59-77

Puterman, M. L. (1994). Markov Decision Processes. John Wiley \& Sons, New York.

Ryan, S.G., Herz, R.H. Iannaconi, T.E. Maines, L.A. Palepu, K.,. Schrand, C. M, and Vincent, L. (2001) SEC Auditor Independence Requirements. Accounting Horizons, 15(4), 373-386. 


\section{Appendix.}

\section{Proof of Proposition 2.}

Let $a_{1}=a^{g}$ be the auditor optimal strategy. Then, the utility function $V(n, 1)$ at the beginning of an engagement satisfies:

$$
\begin{aligned}
V(n, 1)=\mu(f & +\delta(f-C+\delta V(n, 1))) \\
& +(1-\mu)(f+(1-\lambda)(-R-C+\delta V(n, 1))+\lambda \delta V(n, 2)) \\
& =\mu(f+\delta(f-C+\delta V(n, 1))) \\
& +(1-\mu)(f+(1-\lambda)(-R-C+\delta V(n, 1))+\lambda \delta(f-C+\delta V(n, 1)) .
\end{aligned}
$$

Solving for $V(n, 1)$ gives:

$$
V(n, 1)=\frac{f}{1-\delta}+\frac{-\mu \delta C-(1-\mu)(1-\lambda)(C+R)}{(1-\delta)(1+\delta \lambda+\delta \mu-\delta \lambda \mu)}
$$

The policy improvement criterion for $a_{1}=a^{g}$ being an optimal strategy at state $(b, 1)$ then can be expressed by:

$$
\begin{aligned}
f+(1-\lambda)(- & R-C+\delta V(n, 1))+\lambda \delta V(n, 2) \\
& =f+(1-\lambda)(-R-C+\delta V(n, 1))+\lambda \delta(f-C+\delta V(n, 1)) \\
\geq & f-C+\delta V(n, 1) .
\end{aligned}
$$

After inserting the value for $V(n, 1)$, I obtain the following condition on costs:

$$
\begin{aligned}
(1-\lambda)(-R- & \left.C+\delta \frac{-\mu \delta C-(1-\mu)(1-\lambda)(C+R)}{(1-\delta)(1+\delta \lambda+\delta \mu-\delta \lambda \mu)}\right) \\
& +\lambda \delta\left(-C+\delta \frac{-\mu \delta C-(1-\mu)(1-\lambda)(C+R)}{(1-\delta)(1+\delta \lambda+\delta \mu-\delta \lambda \mu)}\right) \\
\geq & -C+\delta \frac{-\mu \delta C-(1-\mu)(1-\lambda)(C+R)}{(1-\delta)(1+\delta \lambda+\delta \mu-\delta \lambda \mu)} .
\end{aligned}
$$

Finally, I solve this inequality for $C$ and obtain:

$$
C \geq C^{* *}=\frac{R(1-\lambda)}{\lambda}(1+\mu \delta) \text {. }
$$

\section{Proof of Proposition 3.}

Let $a_{1}=a^{g}$ be a part of auditor's optimal strategy. Then, the utility function $V(n, 1)$ at the beginning of an engagement satisfies:

$$
\begin{aligned}
V(n, 1)=\mu V & (g, 1)+(1-\mu) V(b, 1) \\
& =\frac{\mu f}{1-\delta}+(1-\mu) \frac{f}{1-\delta \lambda}+\frac{(1-\lambda)(-R-C+\delta V(n, 1))}{1-\delta \lambda} .
\end{aligned}
$$

By rearranging terms, I obtain: 


$$
V(n, 1)=\frac{f}{1-\delta}+\frac{(1-\mu)(1-\lambda)(-R-C)}{(1-\delta \lambda)-(1-\mu)(1-\lambda) \delta} .
$$

The expected utility function is the sum of the discounted stream of future audit fees less the damages the auditor incurs whenever the bad projects he audits fail.

The policy improvement criterion for the certifying being an optimal strategy at state $(b, 1)$ then can be written as follows:

$$
f-C+\delta V(n, 1) \leq \frac{f}{1-\delta \lambda}+\frac{(1-\lambda)(-R-C+\delta V(n, 1))}{1-\delta \lambda}
$$

Inserting the value for $V(n, 1)$ yields:

$$
\begin{aligned}
f-C+\delta\left(\frac{f}{1-\delta}+\frac{(1-\mu)(1-\lambda)(-R-C)}{(1-\delta \lambda)-(1-\mu)(1-\lambda) \delta}\right) \\
\leq \\
\quad \frac{f}{1-\delta \lambda}+\frac{(1-\lambda)(-R)}{1-\delta \lambda}+\frac{(1-\lambda)(-C)}{1-\delta \lambda} \\
+\frac{(1-\lambda) \delta}{1-\delta \lambda}\left(\frac{f}{1-\delta}+\frac{(1-\mu)(1-\lambda)(-R-C)}{(1-\delta \lambda)-(1-\mu)(1-\lambda) \delta}\right)
\end{aligned}
$$

In the infinite horizon decision problem the auditor receives audit fee $f$ in each period of time, therefore, the inequality boils down to the following condition on the costs:

$$
\begin{aligned}
& -C+\delta \frac{(1-\mu)(1-\lambda)(-R-C)}{(1-\delta \lambda)-(1-\mu)(1-\lambda) \delta} \\
& \quad<\frac{(1-\lambda)(-R-C)}{1-\delta \lambda}+\frac{(1-\lambda) \delta}{1-\delta \lambda} \frac{(1-\mu)(1-\lambda)(-R-C)}{(1-\delta \lambda)-(1-\mu)(1-\lambda) \delta}
\end{aligned}
$$

The expression $\frac{(1-\mu)(1-\lambda)(-R-C)}{(1-\delta \lambda)-(1-\mu)(1-\lambda) \delta}$ is a delayed discounted sum of the switching costs and penalties the auditor has to incur each time the audit failure becomes public. On the righthand side, this expression is multiplied by the coefficient $\frac{(1-\lambda) \delta}{1-\delta \lambda}$, which represents the auditor's uncertainty about when his client may fail. Next, I solve this inequality for $C$ and obtain:

$$
C \geq C^{\prime}=\frac{(1-\lambda) R(1-(1-\mu) \delta)}{\lambda(1-\delta)}
$$

\section{Proof of Proposition 4.}

Let $a_{1}=a^{g}$ be a part of the auditor's optimal strategy. Then, the utility function $V(n, 1)$ at the beginning of an engagement satisfies: 


$$
\begin{aligned}
V(n, 1)=\mu V( & g, 1)+(1-\mu) V(b, 1) \\
& =\mu\left(f+\delta(f-C)+\delta^{2} V(n, 1)\right) \\
& +(1-\mu)(f+(1-\lambda)(-R-C+\delta V(n, 1)) \\
& +\delta \lambda(f-(1-\lambda) R-C+\delta V(n, 1))) .
\end{aligned}
$$

Next, I solve this equation for $V(n, 1)$ :

$$
V(n, 1)=\frac{f}{1-\delta}+\frac{\mu \delta(f-C)+(1-\mu)((1-\lambda)(-R-C)+\delta \lambda(-(1-\lambda) R-C))}{(1-\delta)(1+\delta \lambda+\delta \mu-\delta \lambda \mu)} .
$$

Analogously to the case when $a_{1}=a^{b}$, I apply the policy improvement criterion:

$$
\begin{gathered}
f+(1-\lambda)(-R-C+\delta V(n, 1))+\delta \lambda(f-(1-\lambda) R-C+\delta V(n, 1)) \\
\geq f-C+\delta V(n, 1)
\end{gathered}
$$

I insert the value for $V(n, 1)$ and find the following condition on costs:

$$
\begin{aligned}
(1-\lambda)(-R- & \left.C+\delta \frac{\mu \delta(f-C)+(1-\mu)((1-\lambda)(-R-C)+\delta \lambda(-(1-\lambda) R-C))}{(1-\delta)(1+\delta \lambda+\delta \mu-\delta \lambda \mu)}\right) \\
& +\delta \lambda(-(1-\lambda) R-C \\
& \left.+\delta \frac{\mu \delta(f-C)+(1-\mu)((1-\lambda)(-R-C)+\delta \lambda(-(1-\lambda) R-C))}{(1-\delta)(1+\delta \lambda+\delta \mu-\delta \lambda \mu)}\right) \\
& \geq f-C \\
& +\delta \frac{\mu \delta(f-C)+(1-\mu)((1-\lambda)(-R-C)+\delta \lambda(-(1-\lambda) R-C))}{(1-\delta)(1+\delta \lambda+\delta \mu-\delta \lambda \mu)}
\end{aligned}
$$

I solve this inequality for $C$ and find that:

$$
C \geq C^{\prime \prime}=\frac{R(1-\lambda)(1+\delta \lambda)(1+\mu \delta)}{\lambda} .
$$

This proves that the auditor's optimal strategy includes certifying the client's report in the first stage of the engagement when $C \geq C^{\prime \prime}$. 